\title{
A taxonomy of cognitive tasks to evaluate cognitive-motor interference on spatiotemoporal gait parameters in older people: a systematic review and meta- analysis
}

B. Wollesen ${ }^{*^{*}}$ D, M. Wanstrath ${ }^{2}$, K. S. van Schooten ${ }^{3}$ and K. Delbaere ${ }^{3}$

\begin{abstract}
Background: Walking in natural environments can be considered a dual-task (DT) scenario that requires increasing cognitive resources with advancing age. Previous reviews concluded that gait speed under DT conditions is equivalent to gait speed as a single task (ST) in the prediction of future falls in older people. However, without a clear taxonomy, these conclusions might be premature. The aim of this review is to use a taxonomy for classifying cognitive tasks of cognitive-motor interference (CMI) paradigms while walking to identify which task domains lead to more pronounced cognitive-motor decrements due to fall risk and concern about falling (CoF) in older people.

Methods: A systematic literature research following PRISMA guidelines was conducted using MEDLINE, Psych-Info and EMBASE. Inclusion criteria were: older people $\geq 60$ years with a previous fall or CoF, use of a DT paradigm to discriminate fallers and non-fallers, straight overground walking, reported gait measurements during ST and DT conditions. A meta-analysis estimated the effect of DT costs for the cognitive task domain and spatiotemporal gait parameters.
\end{abstract}

Results: $N=3737$ studies were found within the databases. Nineteen studies were included ( $n=14$ for meta-analysis). Fallers and people with CoF showed reduced walking speed for ST and DT conditions. Effects of DT were examined for mental tracking tasks. The combined odds ratio (OR [95\% confidence interval]) for fallers vs. non-fallers for ST was 3.13 $[0.47,5.80]$ with moderate heterogeneity $\left(I^{2}=48 \%\right)$. For DT, the OR was $5.17[2.42,7.93]$ with low heterogeneity $\left(I^{2}=\right.$ 37\%). Comparing participants with and without CoF, the OR for ST was 12.41 [9.97, 14.84] with high heterogeneity $\left(I^{2}=85 \%\right)$ and OR for mental tracking DT was $10.49[7.58,13.40]$ with moderate heterogeneity $\left(I^{2}=51 \%\right)$.

Conclusion: CMI was not significantly different between fallers and non-fallers or people with and without CoF; however, our taxonomy revealed a large variety of cognitive conditions and a higher number of studies using mental tracking tasks, which make it impossible to draw firm conclusions. Future studies should use a more standardised and ecologically valid approach when evaluating the validity of DT gait performance in the prediction of falls, CoF or other agerelated conditions.

Trial registration: This review was registered at Prospero with the ID: CRD42017068912.

Keywords: Falls, Concern about falls, Fear of falling, Ageing, Dual-task, Dual task cost

\footnotetext{
* Correspondence: bettina.wollesen@uni-hamburg.de

'Human Movement Science, University of Hamburg, Mollerstr, 10, 20148

Hamburg, Germany

Full list of author information is available at the end of the article
}

(c) The Author(s). 2019 Open Access This article is distributed under the terms of the Creative Commons Attribution 4.0 International License (http://creativecommons.org/licenses/by/4.0/), which permits unrestricted use, distribution, and reproduction in any medium, provided you give appropriate credit to the original author(s) and the source, provide a link to the Creative Commons license, and indicate if changes were made. The Creative Commons Public Domain Dedication waiver (http://creativecommons.org/publicdomain/zero/1.0/) applies to the data made available in this article, unless otherwise stated. 


\section{Introduction}

Walking in our natural environment can be considered a dual-task (DT) scenario that requires increasing cognitive resources with advancing age. Age-related decline of performance whilst walking in DT situations has been extensively investigated [1-5]. For instance, an age-related decline in gait performance has been observed when conducting arithmetic, memory or visual tasks concurrently with walking $[5,6]$. Walking is not an automated task and requires structural and functional connectivity of neural brain networks. Changes in brain structure are common with ageing and require re-allocation of cognitive resources for fast and efficient operation of neural brain networks $[7,8]$ during complex activities. Higher age is further associated with reduced cognitive processing efficiency (e.g., decrease in nerve conduction speed and increased lateralization) [9], which is in turn associated with a decrease in cognitive performance such as diminished response time, working memory and processing of multiple tasks. These age-related cognitive changes affect daily-life task performance [10]. The level to which walking performance is affected by cognitive-motor interference is typically expressed as the dual-task cost (DTC). This is calculated as the percentage of decrements in performance in a dual- or multi-task relative to single task performance. It is proposed that, with advancing age, sensory and motor aspects of walking performance increasingly require cognitive control and attention. Several studies report a correlation between age-related declines in the sensory and motor system on the one hand and agerelated declines in cognitive functioning on the other hand [11]. There is some evidence that decrements of gait performance in older people with a reduced postural reserve (motor abilities to maintain balance) can be independent of the cognitive performance [12]. Other studies showed that impaired executive function and attention affect walking performance of older fallers independent of physical ability $[13,14]$.

DT paradigms have become prominent to understand cognitive-motor interference (CMI) while walking in old age. These dual-task experiments have demonstrated that the extent to which the cognitive demand affects walking performance is exacerbated in old age [15], people with high risk for falls [16] and people with concerns about falling [17]. People's tendencies to change their gait patterns during complex activities might result in an increased risk of falling [10]. Many studies reported more pronounced impairments of spatiotemporal gait parameters under dual-task conditions (including gait speed, step length, step width and double support time) in fallers compared to non-fallers [18-20]. Cognitive-motor interference in combinations with poorer physical abilities may increase a person's risk of falling even further, especially in situations that require the adoption of a faster gait speed [21]. This is further impacted by poorer judgement of physical abilities, which has been linked to more collisions with oncoming cars in virtual reality experiments [22, 23]. The understanding of cognitive-motor interference in people with high fall risk or concerns about falling during walking under different cognitive dual-task conditions is still quite limited. Moreover, there is little information about which motor and cognitive task combinations require the highest attentional demands in older people and which mechanisms lead to insufficient resource allocation.

\section{Theoretical models to explain cognitive-motor interference}

Several theoretical models have been proposed to explain reduced walking performance in dual-task situations. The central bottleneck theory states that due to an information processing bottleneck only one task can be processed at a time; processing of a second task cannot commence until the first is complete. This bottleneck usually results in a longer response time for one of the two tasks [34-36]. The 4-dimensional multiple resource model [37] proposes that there will be greater interference between two tasks that utilise similar resources. Finally, the attentional resource theory suggests that declines in performance under DT conditions result from interference caused by competing demands for attentional resources, resulting in less attention available to each task [38, 39].

The attentional resource theory might especially apply to people with CoF. CoF is very common in older people and can lead to self-induced restriction of physical and social activities. In its most severe form, it can result in a persistent and dysfunctional disruption of attention. People with higher levels of CoF have difficulties to inhibit or ignore irrelevant information of the environment in the process of balance control. Therefore, CoF may compete for the limited resources of attentional focus to maintain balance control during complex activities [40] resulting in instability and increased fall risk. A meta-analysis by Ayoubi et al. [41] revealed that $\mathrm{CoF}$ is associated with increased gait variability during normal walking. This effect is amplified under DT conditions, due to reduced gait speed and step length (often referred to as cautious gait), especially in older people who also reduce their daily physical activity due to their CoF [42].

Performance is expected to deteriorate in complex situations if there are fewer resources available for performance than are required. Navon [43] defined resources as any internal input that is essential for 
processing and is available in limited quantities at any point in time. Walking requires coordination of peripheral sensory and neuromuscular systems, with higher-level cognitive processing, which gradually decline with age. It is therefore not surprising that with advancing age, cognitive-motor interference becomes more pronounced when performing complex daily activities $[10,36,44]$. Each task requires a reweighting of sensorimotor information depending on the requirements of the additional task [45]. When the sensory system delivers conflicting information, vision will dominate spatial processing, which impacts a person's ability to coordinate sensory and cognitive processing to main upright [45]. In addition, studies indicate that increasing difficulty levels (from DT to multitaskperformance or with different task complexities e.g. from processing speed to decision-making tasks; see Table 1) further amplify the effects of cognitive-motor interference on walking performance [46-51]. Systematic reviews have further highlighted that cognitivemotor interference rises based on the task domain and the individual's abilities and resources [52, 53]. More specifically, tasks including controlled processes or motor components showed more decrements in DT performance of older people.

However, activities that heavily rely on postural control occasionally lead to an improved motor performance when combined with a secondary task [54]. The U-Shaped Non-Linear Interaction Model postulates that, depending on the complexity of the secondary task, motor and balance performance can increase or decrease [55]. For example, there might be a reduction of postural sway as a result of muscle co-contraction while concentrating on the cognitive task [56, 57], whereas postural sway may increase without additional cognitive performance with a secondary task [58]. The Supra-Postural Task Model [59, 60] provides additional details to explain the U-shape relationship between postural control and balance. The theory suggests that in specific situations the motor performance is necessary to reach the goal of the cognitive task (e.g. standing still to read a sign). In contrast to the U-shaped model, in the Supra-Postural Task Model effects are explained by situation awareness and not by task complexity [61].

Finally, the Task Prioritization Model [62] accounts for the strategies that an individual might use during complex activities. It postulates that older people are more likely to prioritize motor performance under threat of a loss of balance [63,64]. This prioritization reduces the cognitive-motor interference and allows for reorganization of the cognitive-motor resources [65] to reduce the risk of falling. However, if the environment poses too many challenges (e.g. elevated surface), task prioritization is not always effective. Yogev-Seligmann and colleagues [66] found that older people with adequate balance abilities and capacity to identify hazards are able to focus on cognitive performance as long as balance is maintained. On the other hand, fallers are not able to shift attention in these situations [67], which could be explained by the impact of poor executive function and attention on walking performance of older fallers [13, 14].

\section{Objectives}

The primary objective of this review was to use a taxonomy for classifying cognitive tasks to gain insight in cognitive-motor interference within the study of falls in older people. Previous reviews concluded that gait speed under DT conditions is equivalent to gait speed as a single task in the prediction of future falls in older people $[50,68]$. However, without a clear taxonomy of cognitive dual tasks, these conclusions might be premature. In addition, little is known about the effects of dual-task settings on older adults with CoF. A clear taxonomy will allow a better understanding of how cognitive-motor interference during complex activities is related to fall risk and concern about falls.

\section{Methods}

\section{Search strategy}

Databases were systematically searched by using OvidSp to search in Medline (1946 to 2019, Week 20), Embase (1974 to 2019, Week 20) and PsycINFO (1806 to 2019, Week 20). The search within the databases was limited to the English and German language. In addition, the reference lists of included articles were searched manually. Two reviewers (BW, MW) independently searched within titles and abstracts to identify all potentially eligible studies. Afterwards, these two reviewers independently assessed full paper copies of the identified potentially eligible studies to determine the studies to be included. Any disagreement on inclusion was resolved by discussion and through arbitration by a third reviewer (KvS, KD).

\section{Inclusion and exclusion criteria}

The inclusion criteria were: (i) older adults $\geq$ mean age of the sample was 60 years with a previous fall or CoF, (ii) the dual-task paradigm was used to discriminate fallers from non-fallers or people with high concerns about falling from people with low concerns about falling, (iii) utilized straight over ground walking at self-selected speed as the primary motor task, (iv) reported gait measurements during both single and dual-task performance, or the effect of dual-tasking on gait performance (more than one gait cycle), (v) clear 


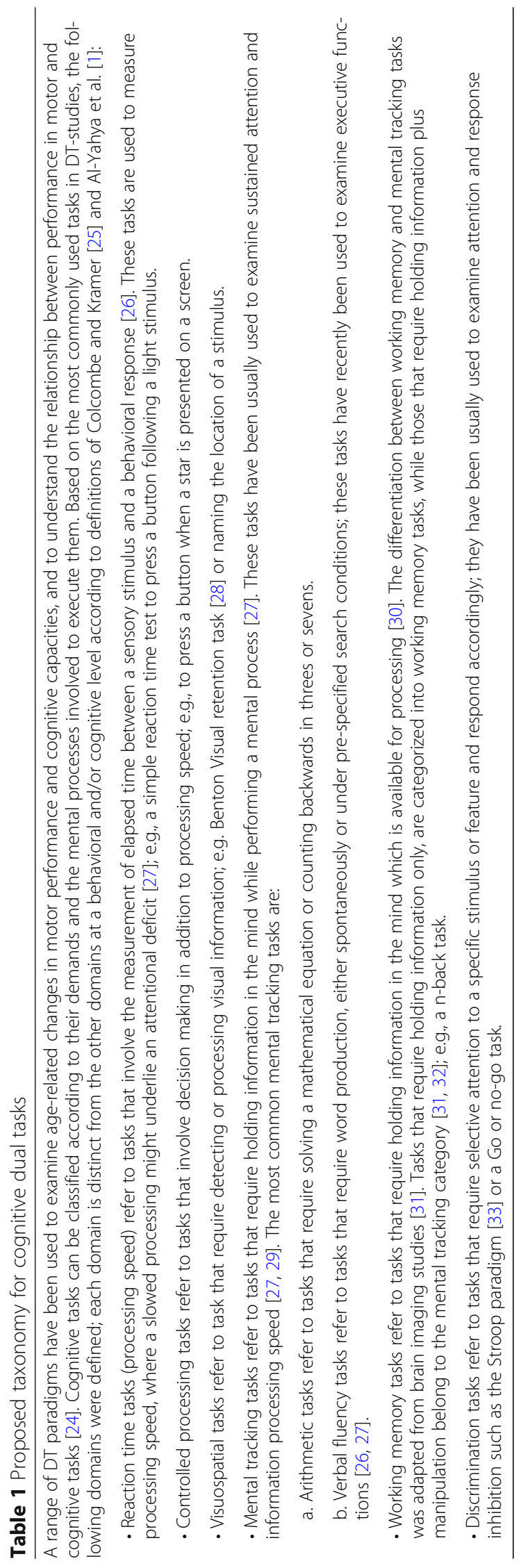


description of the dual-task situation, (vi) reported adequate data to calculate effect sizes either from descriptive or inferential statistics, (vii) interventional studies were included if the effect of dual-tasking on gait at baseline was reported. The exclusion criteria included: (i) population with brain injuries or diagnosed cognitive decline, (ii) physical impairments (e.g. using a cane or walker) and (iii) chronic diseases (e.g., multiple sclerosis or Parkinson's disease). Moreover, studies with a secondary analysis of previous reported results were also excluded.

\section{Selection criteria}

Studies comparing fallers and non-fallers were included if the method section reported of the number of falls. Prospective studies were considered if they compared fallers and non-fallers at baseline (retrospective) or at the follow-up measurement und ST and DT conditions.

Studies addressing CoF were included if they classified the participants according to the "falls efficacy scale international (FES-I)" [69] score, the activities-specific balance confidence $(\mathrm{ABC})$ scale [70] or if they asked the participants using a single item question if they were afraid of falling during activities of daily life.

Studies that included walking under DT conditions were included. This includes studies that investigated at least one walking task (in a DT setting; according to the definitions of spatiotemporal gait parameters addressed in Table 2), studies that compare ST and DT performance, and studies that investigated DT performance in healthy or balance-impaired (fallers) older adults in either a randomized control trail (RCT), an experimental-control group design or an old-young comparison. Moreover, studies with a secondary motor task were also included. Additionally, every concurrent task was assigned to a "stimulus-response-condition" (visual-verbal, visual-manual, auditory-verbal, auditory- manual) and classified according to our taxonomy of cognitive tasks (see Table 1).

\section{Quality assessment}

Quality assessment of the included articles was based on the Standard Quality Assessment Criteria (SQAC) for evaluating primary research papers proposed by the Alberta Heritage Foundation for Medical Research [71]. As the review did not focus on RCTs, the quality criteria for RCTs were not assessed. The quality criteria, as described in SQAC, were: (1) sufficient description of the question/objective; (2) appropriate study design; (3) appropriate method of participant selection or source of information/ input variables; (4) sufficient description of participant characteristics; (5) report of means of assessment with outcome measures well defined and robust" to measurement or misclassification bias (6) appropriate sample size; (7) appropriate analytic methods and method description; (8) report of estimate of variance in main results; (9) control for confounding; (10) sufficiently detailed report of results; and (11) conclusions supported by the results.

Participant selection was verified by comparing the sample with the conclusions drawn from the experimental results. A full point for appropriate sample size was given when either an a priori calculation of sample size had been described or the sample size was a full cohort. Based on the analytic methods employed (8), important statistical values (according to the APAManual [72]) had to be included to obtain a full quality score. BW and MW or KvS performed the assessment independently and the results presented in Table 3 were concurred on. Each criterion scored one point if partly fulfilled and two points if completely fulfilled. Points were added up and resulted in the quality score. The necessary score for a study of high quality was defined to be 17 out of $22(75 \%)$ and $10-16$ points for standard quality according to the SQAC. No point was

Table 2 Spatiotemporal gait parameters

\footnotetext{
Gait - the medical term used to describe the locomotor movement of walking - is simple in terms of execution, but complex in terms of biomechanics and motor control [73]. During steady-state straight forward gait, commonly examined gait variables can be classified into parameters of rhythm (e.g. single and double support time or cadence) and pace (e.g. speed or stride length). This review follows the Guidelines for Assessment of Gait and Reference Values for Spatiotemporal Gait Parameters in Older Adults [73] by defining spatiotemporal gait parameters as:

- Stride length: a stride is the distance from heel strike of one extremity to the next heel strike of the same extremity. Stride length is the distance that one part of a foot travels between the same instant in two consecutive gait cycles.

- Step length: step length is the distance that one part of the foot travels in front of the same part of the other foot during each step.

- Cadence: measure of the number of steps per unit time. Cadence increases if step length shortens when gait speed is held constant.

-Walking speed: distance travelled divided by the ambulation time. Speed was expressed in centimetres per second ( $\mathrm{cm} / \mathrm{sec}$ ).

- Double support time: amount of time spent with both feet in contact with the ground. The gait cycle is divided into the stance phase, when the foot is in contact with the floor, and the swing phase, when it is not. The double support time is approximately $20 \%$ of the gait cycle during which both feet are in ground contact.
} 


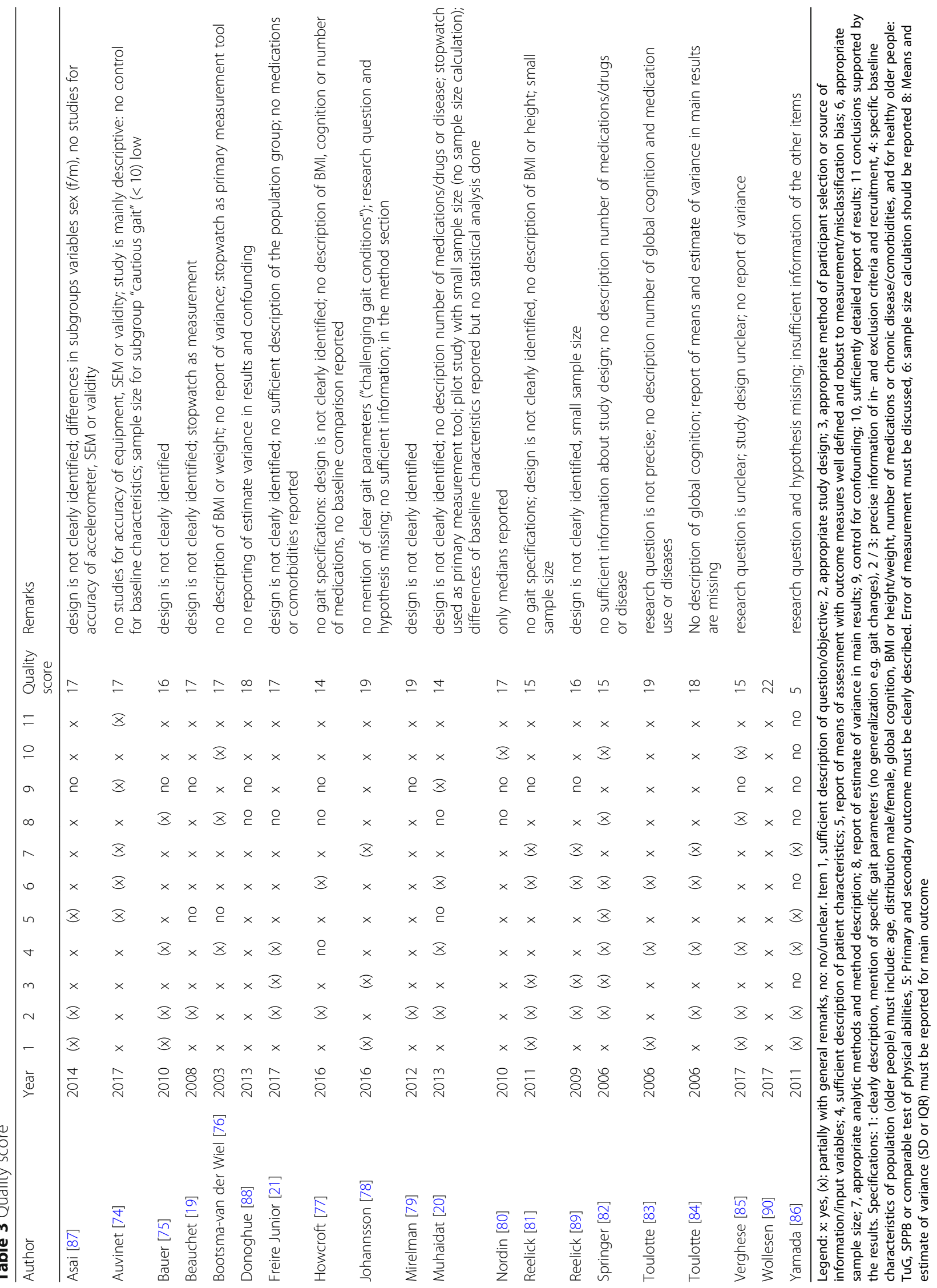


given if general remarks had to be made (indicated by brackets; Table 3). Moreover, we reported some general methodological issues (cf. column general marks). Studies were included in the meta-analysis if they had quality score of 7 or more.

\section{Data extraction}

Table 4 provides an overview of all included studies including the authors, year of publication, study design and aims, population with discrimination to fallers/non-fallers or participants with concerns or no CoF, observed walking parameters and description of the DT setting. The main results of the studies were extracted to Table 5. This includes task order, outcome measures used to assess and report the concurrent tasks performance and instructions given to participants, and study results. Data were recorded as a mean and standard deviation (SD) if reported, with sample size and number analyses in each group (fallers vs. nonfallers or participants with concerns or no CoF).

\section{Statistical analysis of the meta-analysis}

For each of the outcome variables of interest (gait speed, cadence, stride length, step length; see Table 2) we collected the gait data for single and dual-task performance. The gait data was presented as differences in means (MD), since the outcome measurements were made or could be converted on the same scale (e.g., meters per seconds). Most of the studies reported means and SDs permitting effect size estimation, otherwise, they were derived from other summary statistics reported in the articles, such as $t$ values or $p$-values. The gait data from individual studies were then pooled in meta-analyses to estimate the overall effect of cognitive-motor interference of gait. Studies were grouped by cognitive task domain and individual metaanalyses were conducted for each outcome: gait speed, cadence, stride length and step length.

In order to determine whether studies shared the same overall effect size or whether the overall effect for a given outcome was modified by certain factors, we conducted a subgroup analyses on studies that directly compared two factors of interest (e.g., arithmetic task vs. verbal fluency tasks) or two groups of participants (e.g., fallers vs. nonfallers) within the same study. Subgroup analyses were conducted using a mixed-effects model and the summary effects within subgroups were computed using a randomeffects model. Moreover, to further analyse the differences between fallers and non-fallers as well as participants with and without CoF, DTC were calculated by subtracting the $\mathrm{DT}$ values from the ST values. A random-effects model with a generic inverse variance method was used in the pooled analyses, which gives more weight to studies with less variance. Results are presented as effect size with 95\% confidence interval (CI) and respective values for null hypothesis tests (e.g., cognitive-motor interference has no effect on gait). Heterogeneity between studies was investigated by calculating the Q-value and $\mathrm{I}^{2}$ statistic which quantified the proportion variation that is due to heterogeneity rather than chance. Quantitative syntheses and meta-analyses were produced using Review Manager 5 Software (RevMan 5).

\section{Results}

Databases and references identified 2,670 unique articles for consideration. After abstract consideration and title screening, a total of 71 studies were included for further consideration. Reasons for exclusion were studies using participants with neurological disease (e.g., Multiple Sclerosis, Stroke), studies using obstacle negotiation or Reviews. After applying the inclusion criteria, 19 studies were assessed for quality and 16 papers were included in the meta-analysis (cf. Fig. 1; for excluded studies cf. Table 6 and Table 7).

Thirteen studies showed high quality scores $(>16)$ and seven studies were of good quality (according to [71]). The study by Yamada et al. [86] was excluded due to a quality score $<10$. Table 4 gives an overview of all included studies addressing the comparison of fallers vs. non-fallers and participants with and without concerns about falling. The study by Wollesen et al. [90] could not be integrated into the meta-analysis because they used a fixed gait speed in their measurement design.

\section{Fallers vs. non-fallers}

\section{Description of the included studies comparing fallers and} non- fallers $(N=15)$

The mean age of the study population was between 67 years [21, 84, 85] and 87 years [19]. The sample sizes of the studies varied between $N=16[84,85]$ and $N=1350$ [78].

Five studies included a prospective design [19, 74, $76,77,85]$.

The included studies used the following dual-task settings:

- Arithmetic tasks: $n=7$ studies used counting backward tasks [19, 20,74, 75, 80-82], conducted as counting in steps of one $(n=3)$, three $(n=3)$ or seven $(n=3)$ (cf. Table 3).

- Verbal fluency tasks: $n=7$ studies used verbal fluency tasks [20, 21, 75-77, 80, 81]

- Motor tasks: $n=5$ studies used a motor task [20, 21, 80, 83, 85]

- Other tasks: visuo-spatial task [20], Stroop task [20], listening and memory task [82] and reciting of letters of the alphabet [85].

- A total number of six studies analysed more than one task [20, 21, 75, 80-82]. 


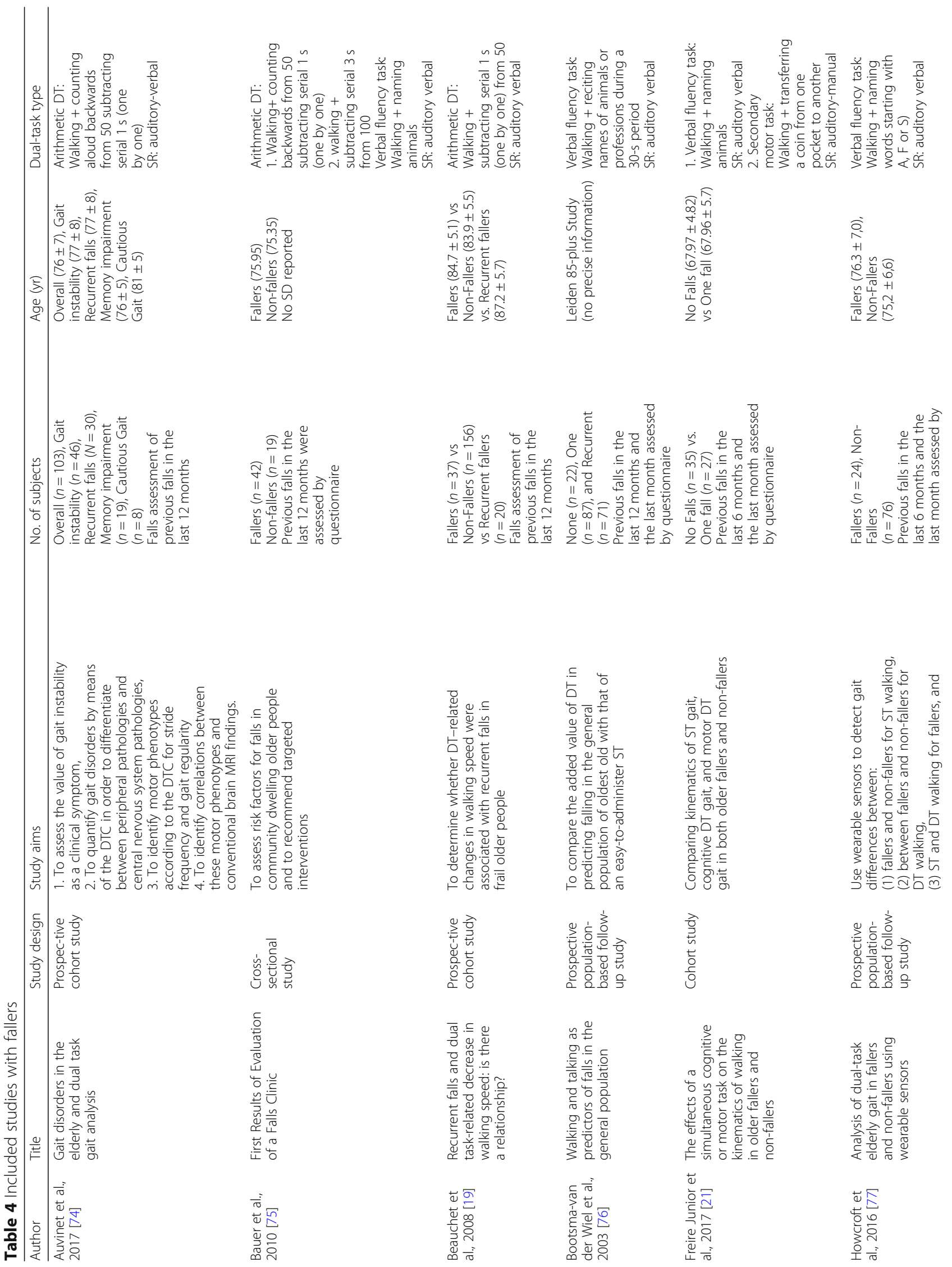




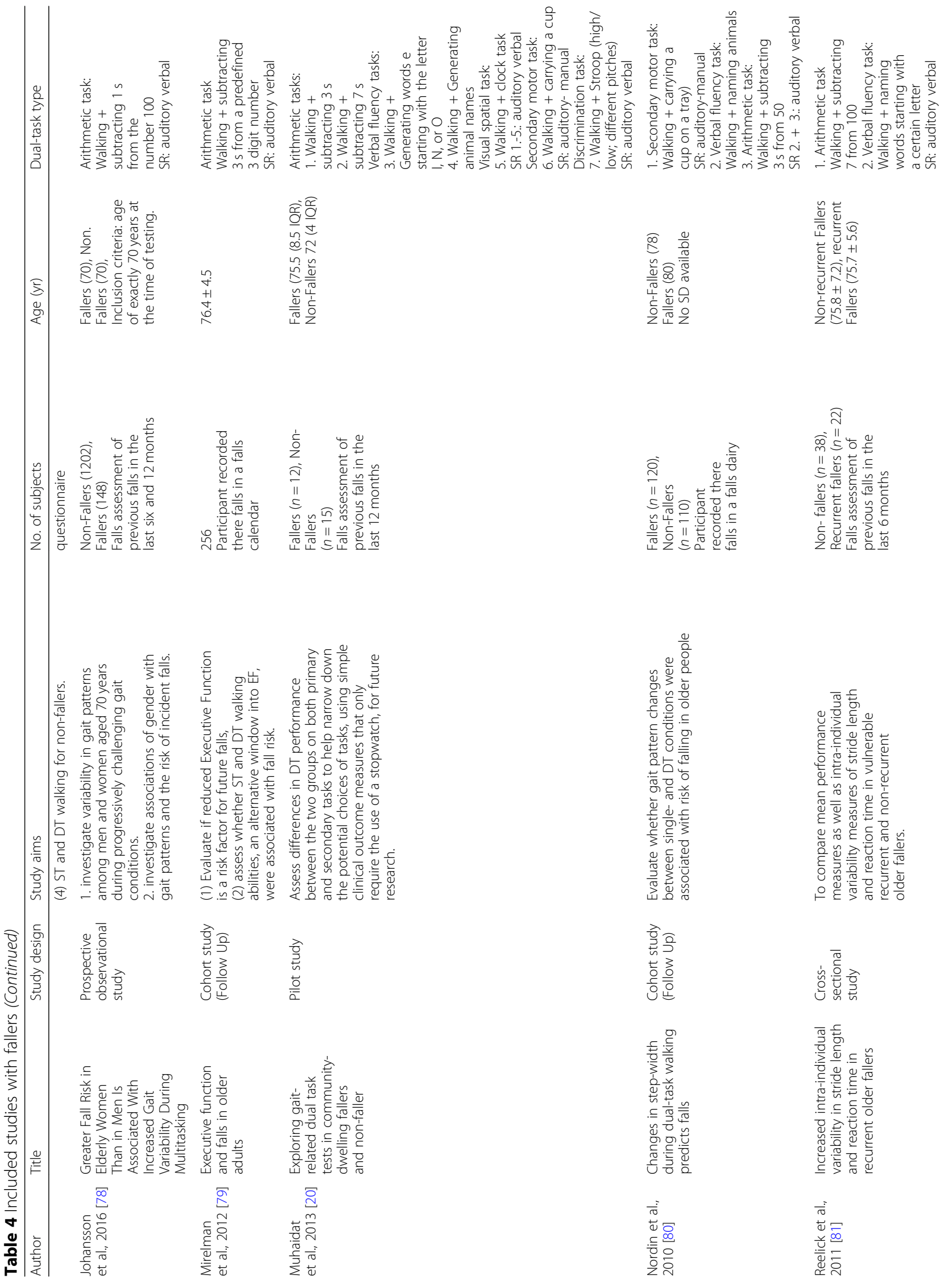




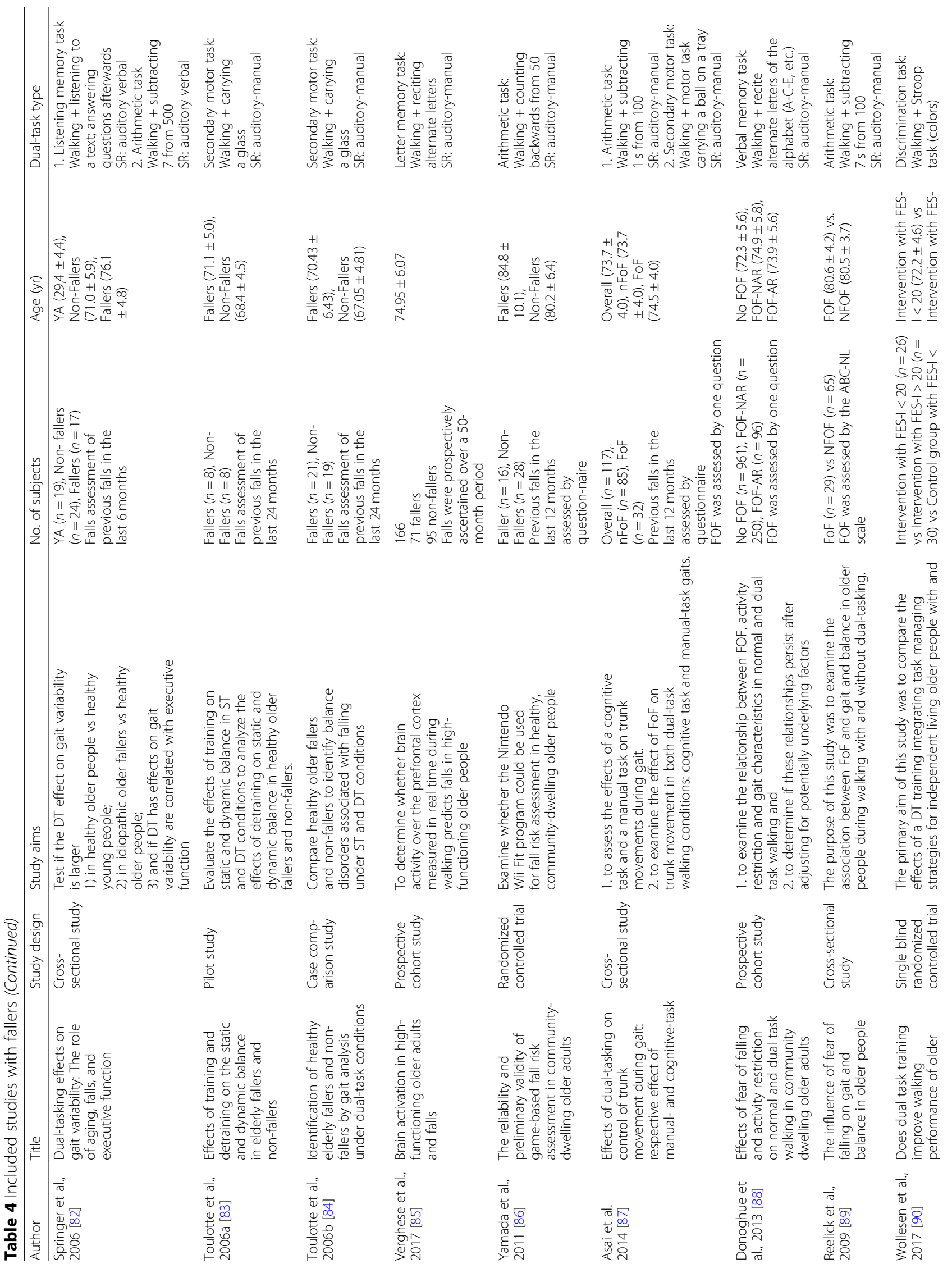




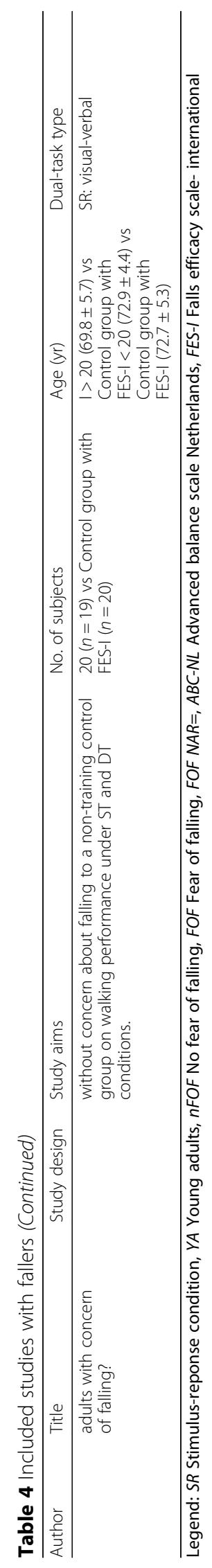




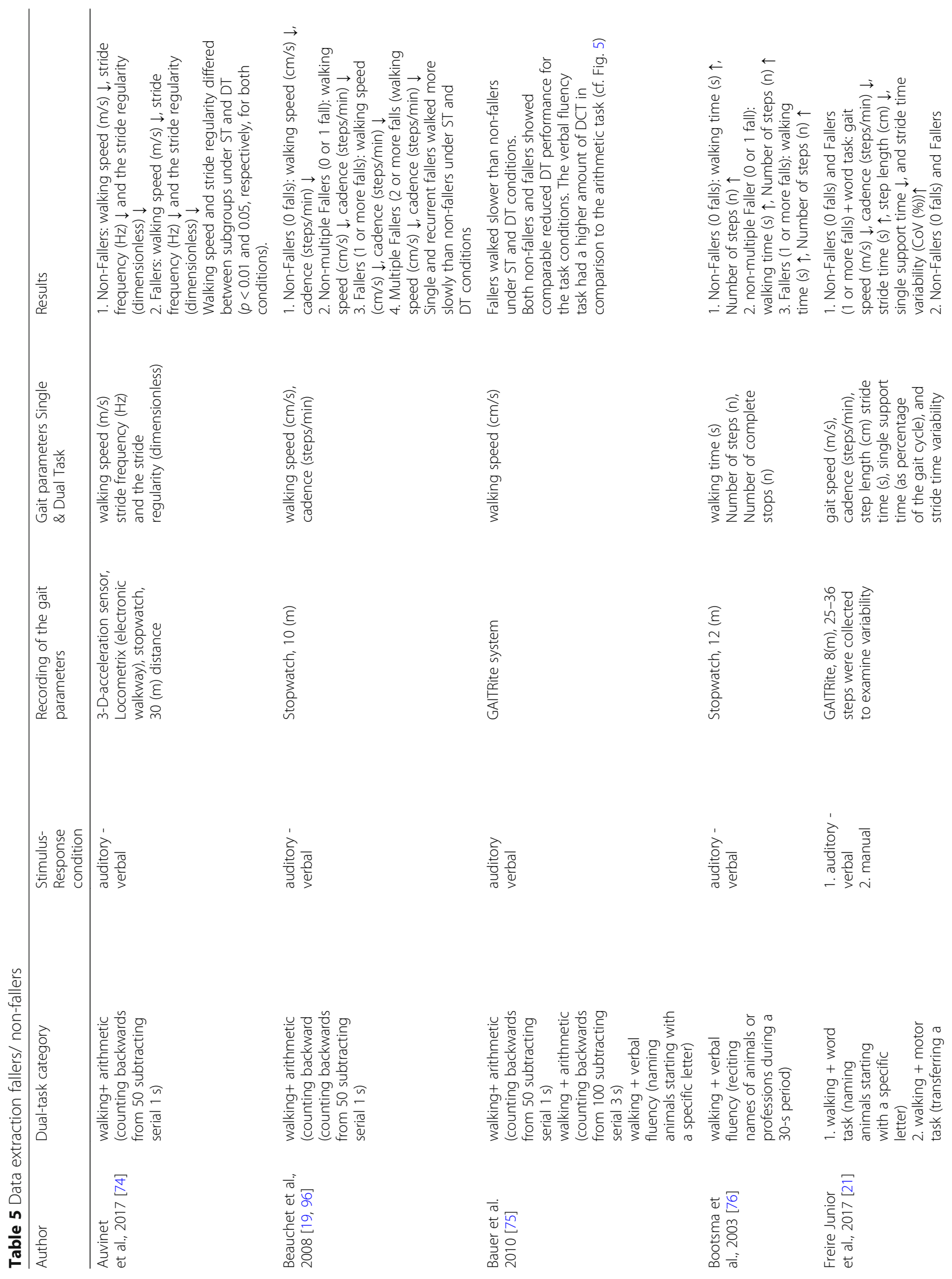




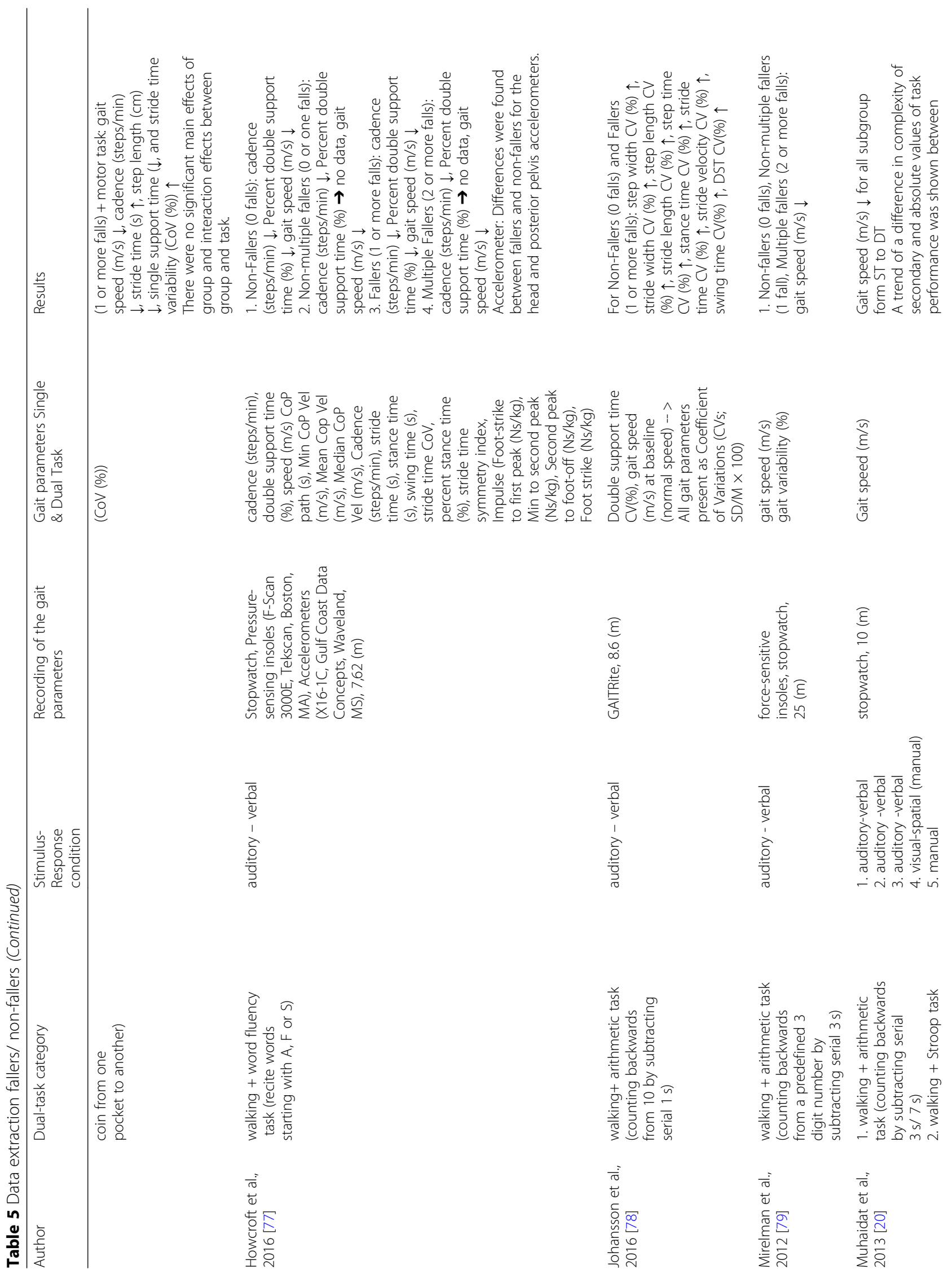




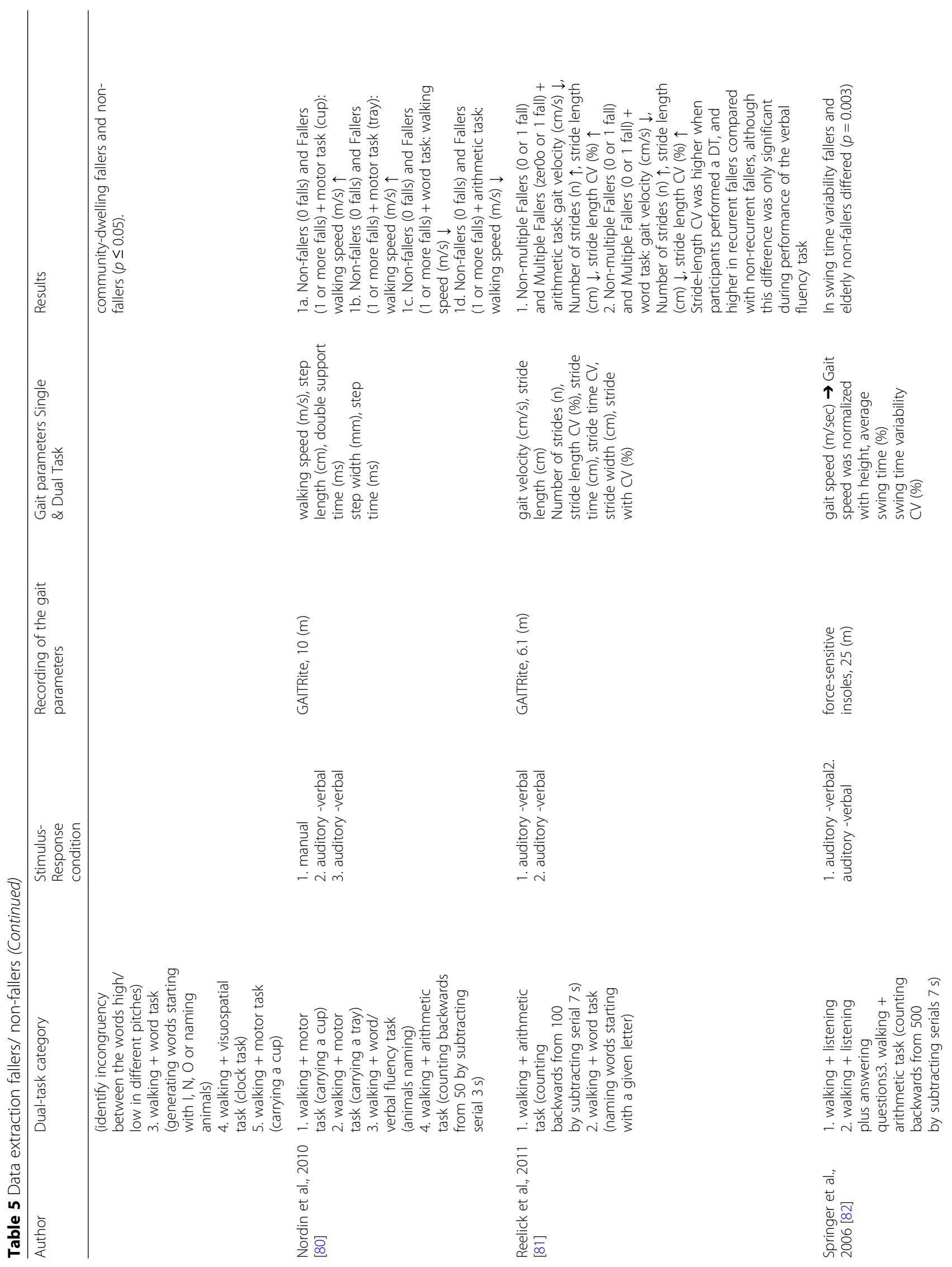




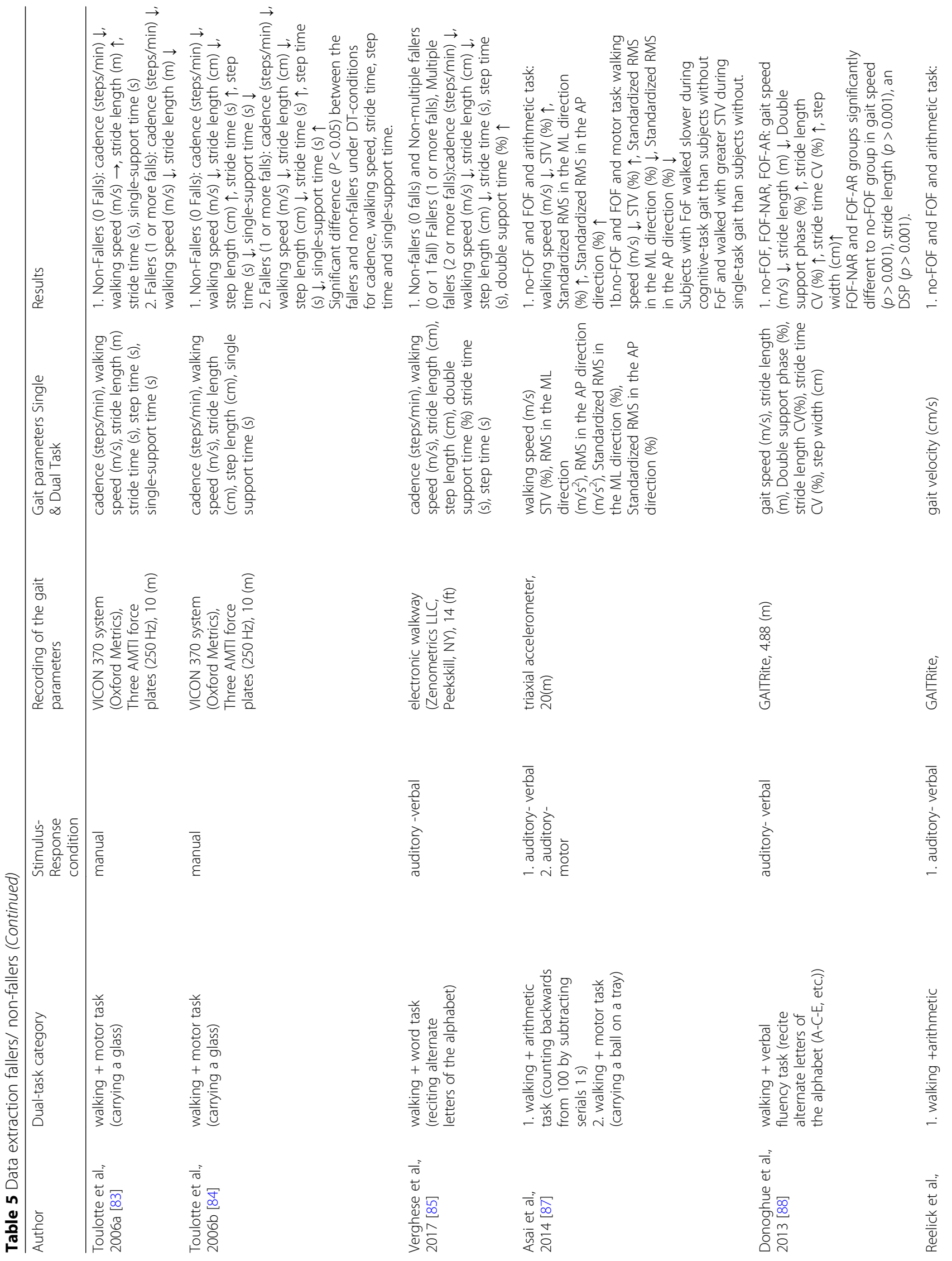




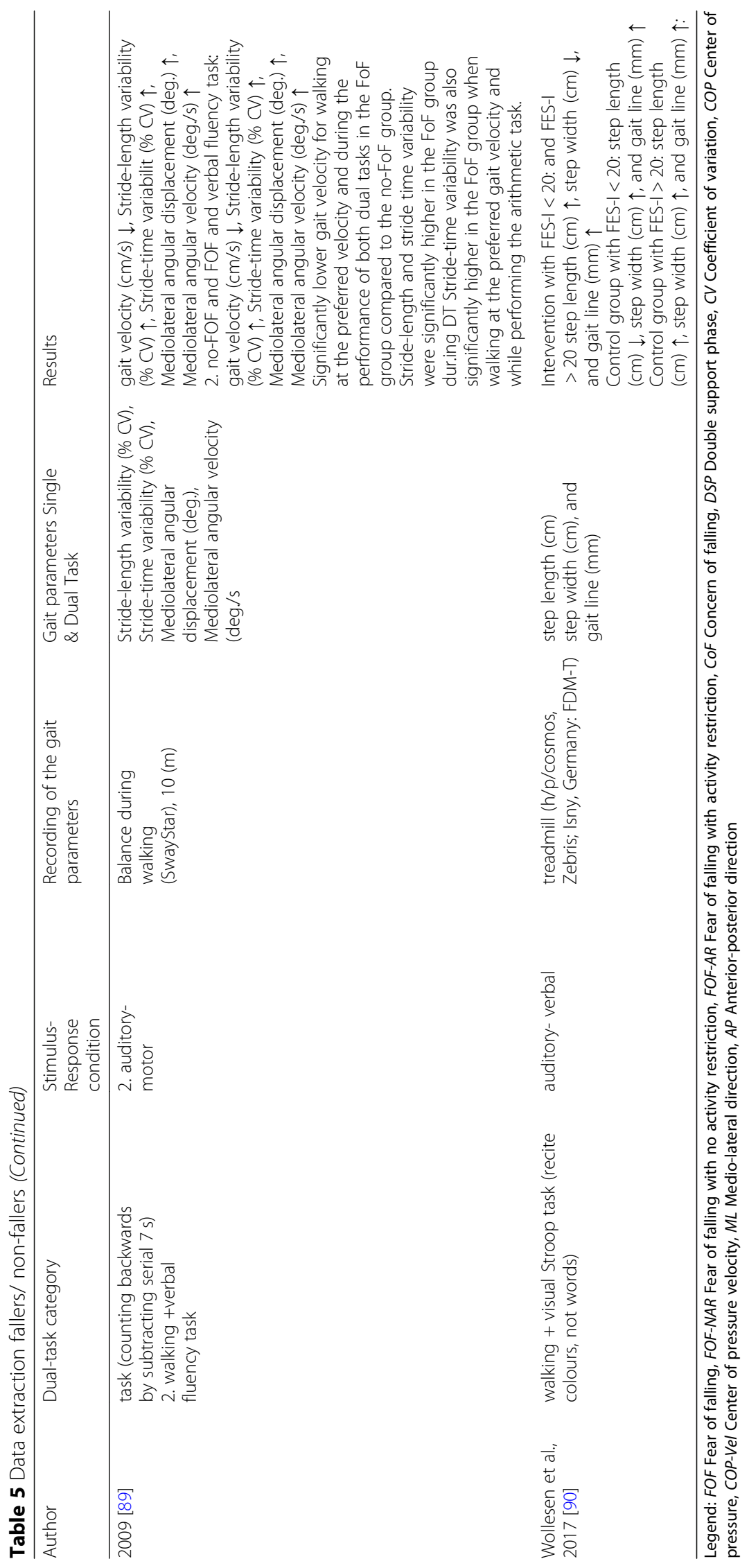




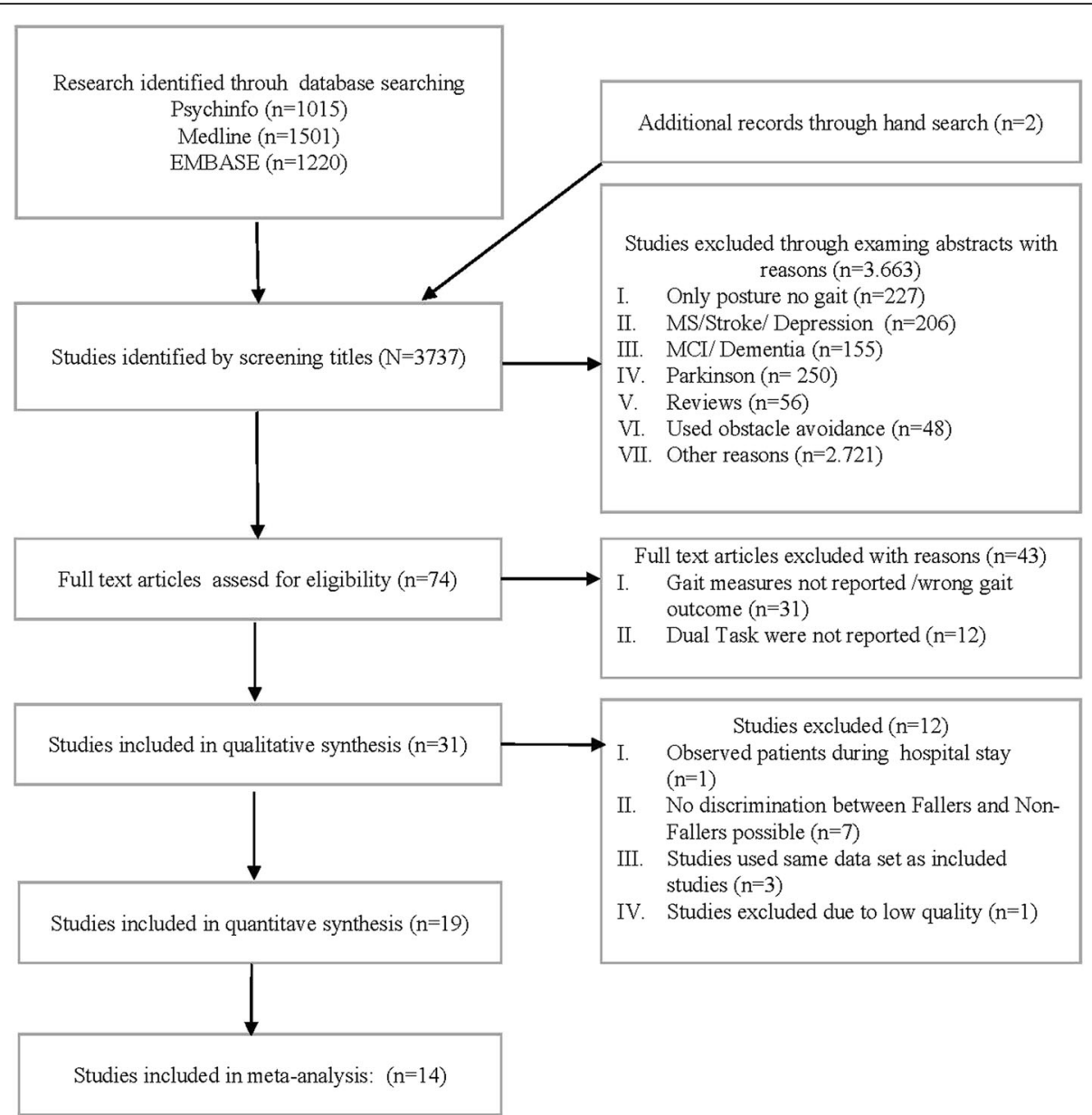

Fig. 1 Flow chart of the systematic review procedure

Overall, the studies comparing fallers and nonfallers examined 32 different gait quality variables. Gait speed or velocity was assessed by $n=14$ studies [19-21, 74, 75, 77-85]. Other gait measures included duration to walk a defined distance $(n=2)[19,77]$, step length $(n=3)[21,80,85]$, stride length $(n=4)$ [14, 83-85], cadence $(n=6)[19,21,77,83-85]$, step time $(n=3)$ [80, 83, 85], stride time $(n=5)$ [21, 77, $81,83,85]$ and double support time $(n=3)$ [77, 80, 85]. Several studies used gait parameters of variability ( $n=14$; eg.: stride time variability $(n=3)$, gait speed variability $(n=2)$ and swing time variability $(n=2))$. In addition, some studies focused on Center of pressure $(\mathrm{CoP})$ or Center of mass $(\mathrm{CoM})$ displacements, or mechanical power in anterior (AP) and mediolateral (ML) direction during gait cycles. These outcomes were not included into the meta-analysis because of lack of consistency in calculation methods among studies or infrequent use. To measure gait characteristics, a stopwatch $(n=6$; from $10 \mathrm{~m}$ up to $30 \mathrm{~m}$ distance), the GAITrite rite system or another electronic walkway ( $n=8$; from $8 \mathrm{~m}$ up to $12 \mathrm{~m}$ ), camera systems (e.g., Vicon $n=3$ ) or insoles (e.g., F-Scan $n=3$ ) were used.

\section{Differences on cognitive-motor dual task performance between non-fallers and fallers}

Four studies could not be integrated into the metaanalysis because the mean values and SD for the analysed gait data were not reported in comparison of non-fallers and fallers and unavailable after attempting to contact the authors $[76,78,81]$. Independent of the task settings, there were no differences of the gait decrements under DT conditions between fallers and non-fallers (cf. Table 5). Mostly, fallers showed reduced performance of the spatiotemporal gait parameters in comparison to non-fallers. Only two studies used a coefficient of variation $[81,82]$ and revealed significant differences between fallers and non-fallers with increased variation in fallers. Reelick [81] found a significantly reduced walking performance for the verbal fluency task in comparison to the arithmetic task. Nordin et al. [80] 
Table 6 Excluded paper

\begin{tabular}{ll}
\hline Excluded papers & Reason for exclusion \\
\hline Beauchet, O., Allali, G., Annweiler, C., Berrut, G., Maarouf, N., Herrmann, F. R., \& & Similar study with the same data set included in the study \\
$\begin{array}{l}\text { Dubost, V. (2008). Does change in gait while counting backward predict the } \\
\text { occurrence of a first fall in older adults? Gerontology, 54(4), 217-223. [96] }\end{array}$ & \\
Faulkner, K. A., Redfern, M. S., Cauley, J. A., Landsittel, D. P., Studenski, S. A., & $\begin{array}{l}\text { No discrimination between Fallers and Non-Fallers possible } \\
\text { for ST and DT gait data }\end{array}$
\end{tabular}
and a history of recurrent falls: Association between poorer performance and a history of recurrent falls. Journal of the American Geriatrics Society, 55(4), 570-576. [10]

Kressig, R. W., Herrmann, F. R., Grandjean, R., Michel, J. P., \& Beauchet, O. (2008). Gait variability while dual-tasking: Fall predictor in older inpatients? Aging Clinical \& Experimental Research, 20(2), 123-130. [97]

Hadjistavropoulos, T., Carleton, R. N., Delbaere, K., Barden, J., Zwakhalen, S., Fitzgerald, B., et al. (2012). The relationship of fear of falling and balance confidence with balance and dual tasking performance. Psychology \& Aging, 27(1), 1-13. [98]

Halvarsson, A., Oddsson, L., Olsson, E., Faren, E., Pettersson, A., \& Stahle, A. (2011). Effects of new, individually adjusted, progressive balance group training for elderly people with fear of falling and tend to fall: A randomized controlled trial. [Erratum appears in Clin Rehabil. 2012 Nov;26(11):1055 Note: Oddsson, Lars [added]]. Clinical Rehabilitation, 25(11), 1021-1031. [99]

Halvarsson, A., Franzén, E., Farén, E., Olsson, E., Oddsson, L., \& Ståhle, A. (2013). Long-term effects of new progressive group balance training for elderly people with increased risk of falling - a randomized controlled trial. Clinical Rehabilitation, 27(5), 450-458. [100]

Herman, T., Mirelman, A., Giladi, N., Schweiger, A., \& Hausdorff, J. M. (2010). Executive Control Deficits as a Prodrome to Falls in Healthy Older Adults: A Prospective Study Linking Thinking, Walking, and Falling. The Journals of Gerontology Series A: Biological Sciences and Medical Sciences, 65A(10), 1086-1092. [101]

MacAulay, R. K., Allaire, T. D., Brouillette, R. M., Foil, H. C., Bruce-Keller, A. J., Han, H., et al. (2015). Longitudinal assessment of neuropsychological and temporal/spatial gait characteristics of elderly fallers: Taking it all in stride. Frontiers in Aging Neuroscience, 7 2015. [102]

Rinaldi, N. M., \& Moraes, R. (2016). Older adults with history of falls are unable to perform walking and prehension movements simultaneously. Neuroscience, 316, 249-260. [103]

Rogan S., Taeymans J., Bangerter C., Simon S., Terrier P., Hilfiker R. (2019). Einfluss von Einfach- und Doppelaufgaben auf Gangstabilitat und Ganggeschwindigkeit bei alteren Menschen: Eine explorative Studie, Influence of single and dual tasks on gait stability and gait speed in the elderly: An explorative study. Zeitschrift fur Gerontologie und Geriatrie.52, (1), 23-27 [104]

Yamada, M., Aoyama, T., Nakamura, M., Tanaka, B., Nagai, K., Tatematsu, N., et al. (2011). The reliability and preliminary validity of game-based fall risk assessment in community-dwelling older adults. Geriatric Nursing, 32(3), 188-194. [86]

Yogev, G., Plotnik, M., Peretz, C., Giladi, N., \& Hausdorff, J. M. (2007). Gait asymmetry in patients with Parkinson's disease and elderly fallers: When does the bilateral coordination of gait require attention? Experimental Brain Research, 177(3), 336-346. [105]

Observed Inpations and only falls in hospital

No discrimination between Fallers and Non-Fallers possible

No discrimination between Fallers and Non-Fallers possible

No discrimination between Fallers and Non-Fallers possible

Similar study with the same data set included in the study

No mean and SD discrimination between Fallers and Non-Fallers possible

No discrimination between Fallers and Non-Fallers possible

No discrimination between Fallers and Non-Fallers possible

Similar study with the same data set included in the study

Table 7 Excluded paper meta-analysis

\begin{tabular}{ll}
\hline Excluded papers & Reason for exclusion \\
\hline Bootsma-van, d., Gussekloo, J., de, C., van, E., Bloem, B. R., \& Westendorp, R. G. (2003). Walking & No Means and SD (only Median and IQR) \\
and talking as predictors of falls in the general population: The Leiden 85-Plus Study. & \\
Journal of the American Geriatrics Society, 51(10), 1466-1471. & No mean and SD discrimination between \\
Johansson, J., Nordström, A., \& Nordström, P. (2016). Greater Fall Risk in Elderly Women Than & Fallers and Non-Fallers possible \\
in Men Is Associated With Increased Gait Variability During Multitasking. Journal of the American & \\
Medical Directors Association, 17(6), 535-540. & No mean and SD discrimination between \\
Reelick, M. F., Kessels, R. P., Faes, M. C., Weerdesteyn, V., Esselink, R. A., \& Rikkert, M. G. O. (2011). & Fallers and Non-Fallers possible \\
Increased intra-individual variability in stride length and reaction time in recurrent older fallers. &
\end{tabular}
Aging clinical and experimental research, 23(5-6), 393-399.LL 
also revealed differences for their task conditions; gait speed increased for the motor-tasks (carrying a cup or a tray) and gait speed decreased for the cognitive conditions (verbal fluency and counting backwards) fallers compared to non-fallers.

\section{Results of the meta-analysis fallers vs. non-fallers}

The forest plot of Fig. 2 shows significant mean difference of 3.32 [95\% confidence interval $0.66-5.99$ ] between non-fallers and fallers for ST gait speed with reduced performance for fallers. However, these results were heterogeneous $\left(\mathrm{I}^{2}=39 \%\right.$; cf. Fig. 2). There were no effects for step length or stride length. Under DT conditions, fallers had a reduced gait speed in comparison to non-fallers with a mean difference of 6.10 [2.239.98] ( $\mathrm{I}^{2}=44 \%$; cf. Fig. 3$)$.

Figure 4 repeats the findings for gait speed under ST and DT conditions and shows the mean difference in DTC (defined as DT minus ST). The meta-analysis showed that there were higher decrements in gait speed for fallers in comparison to non-fallers under DT conditions. However, if the DTC were calculated (Fig. 4), there were no reduced DTC observed for non-fallers.

Figure 5 visualizes the DTC for the different cognitive task domains. Increased DTC for fallers compared to non-fallers could only be observed for verbal fluency and motor dual-tasks but failed to be significant. The overall effect of the different task conditions was also not significant.

\section{Participants with concerns about falling vs no concerns about falling \\ Description of the includes studies $(N=4)$ comparing participants with $\mathrm{CoF}$}

The mean age of the study population was 69.8 years [90] up to 80.6 years [89]. Sample sizes varied between $N=85$ [90] and $N=1307$ [88]. The included studies used different dual-task settings:

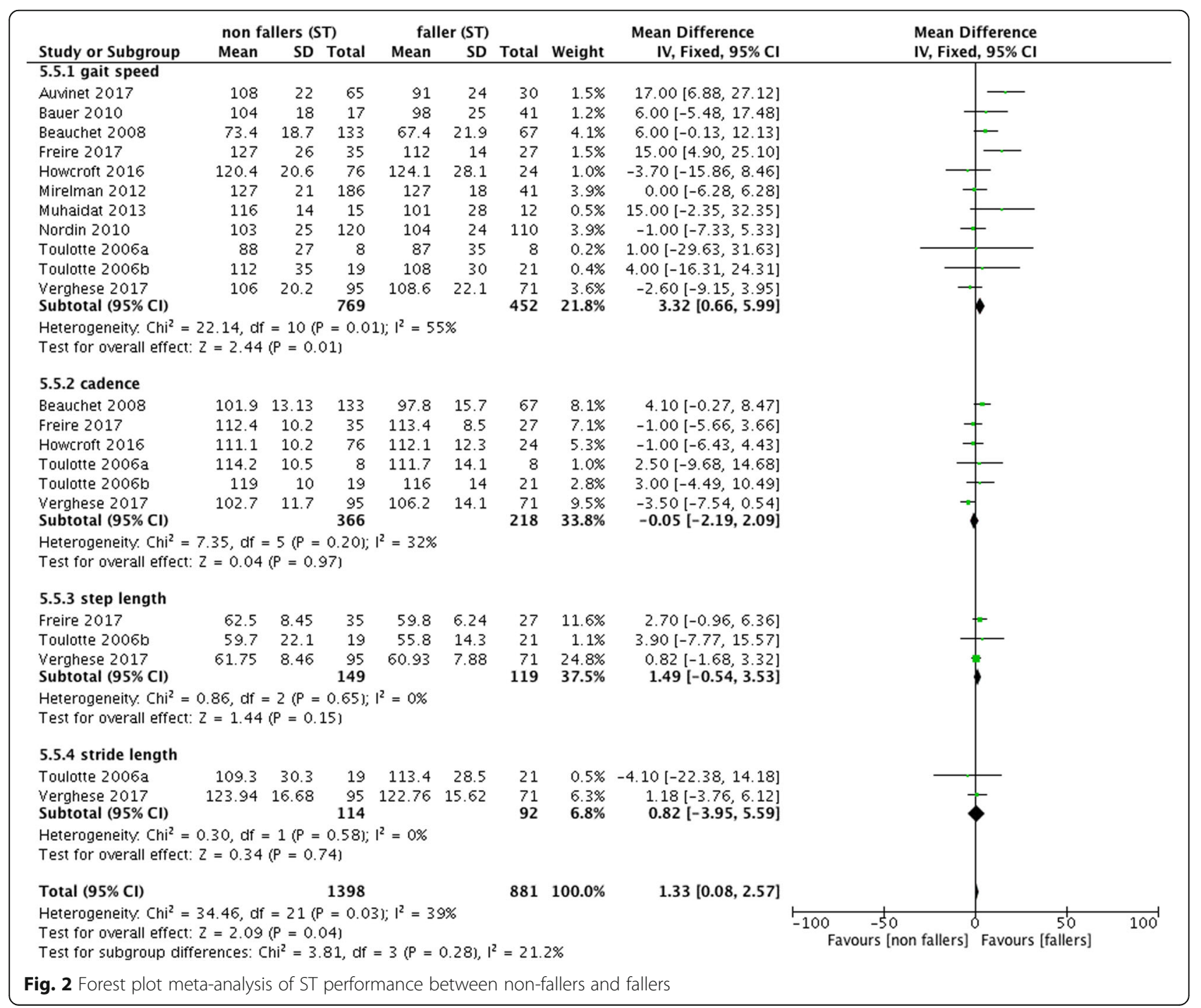




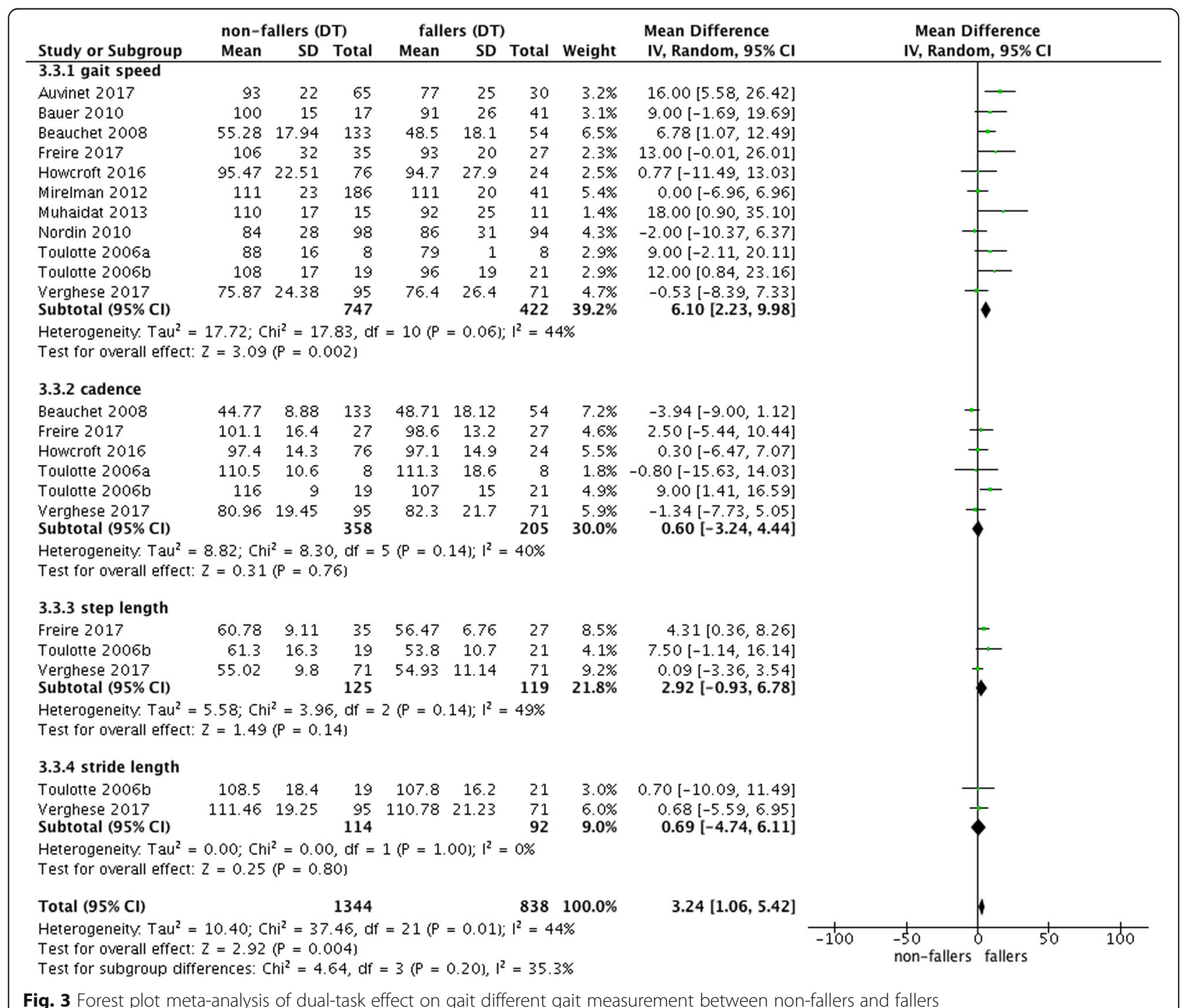

- Arithmetic tasks: The study by Reelick [100] used a counting backward tasks (subtracting $7 \mathrm{~s}$ ) and the study by Asai [87] used a counting backward task (subtracting 1 s) (cf. Table 4).

- Verbal fluency tasks: Donoghue et al. [88] (recite alternative letters of the alphabet) and Reelick et al. [89] (naming animal species as much as possible) used a verbal fluency task.

- Other tasks: The RCT by Wollesen et al. [90] was conducted with a visual-verbal Stroop task.

Studies comparing participants with and without CoF examined 16 different gait variables (cf. Table 5 ); i.e. gait speed $(n=3)$, stride time variability $(n=1)$, step width $(n=2)$, step length $(n=1)$, stride length $(n=2)$. Two studies used different variability calculations $(n=2)$. Moreover, two studies $[87,89]$ focused on CoP or CoM displacements in AP and ML direction during gait cycles. To measure gait performance, the GAITrite system or another electronic walkway $(n=2$; from $5 \mathrm{~m}$ up to 10 $\mathrm{m})$, a triaxial accelerometer $(n=1)$ or a treadmill $(n=1)$ were used (cf. Table 5).

\section{Differences on cognitive-motor-performance between participants with and without concerns about falling}

As reported in Table 5 participants with and without CoF showed comparable DTC. Moreover, all studies showed that participants with CoF had a poorer walking quality (e.g., reduced walking speed with accompanying step length or increased variability) in the ST condition compared to people without CoF. With regard to the different task settings, the two studies that examined two different cognitive dual-tasks found different reactions in all participants according to the 


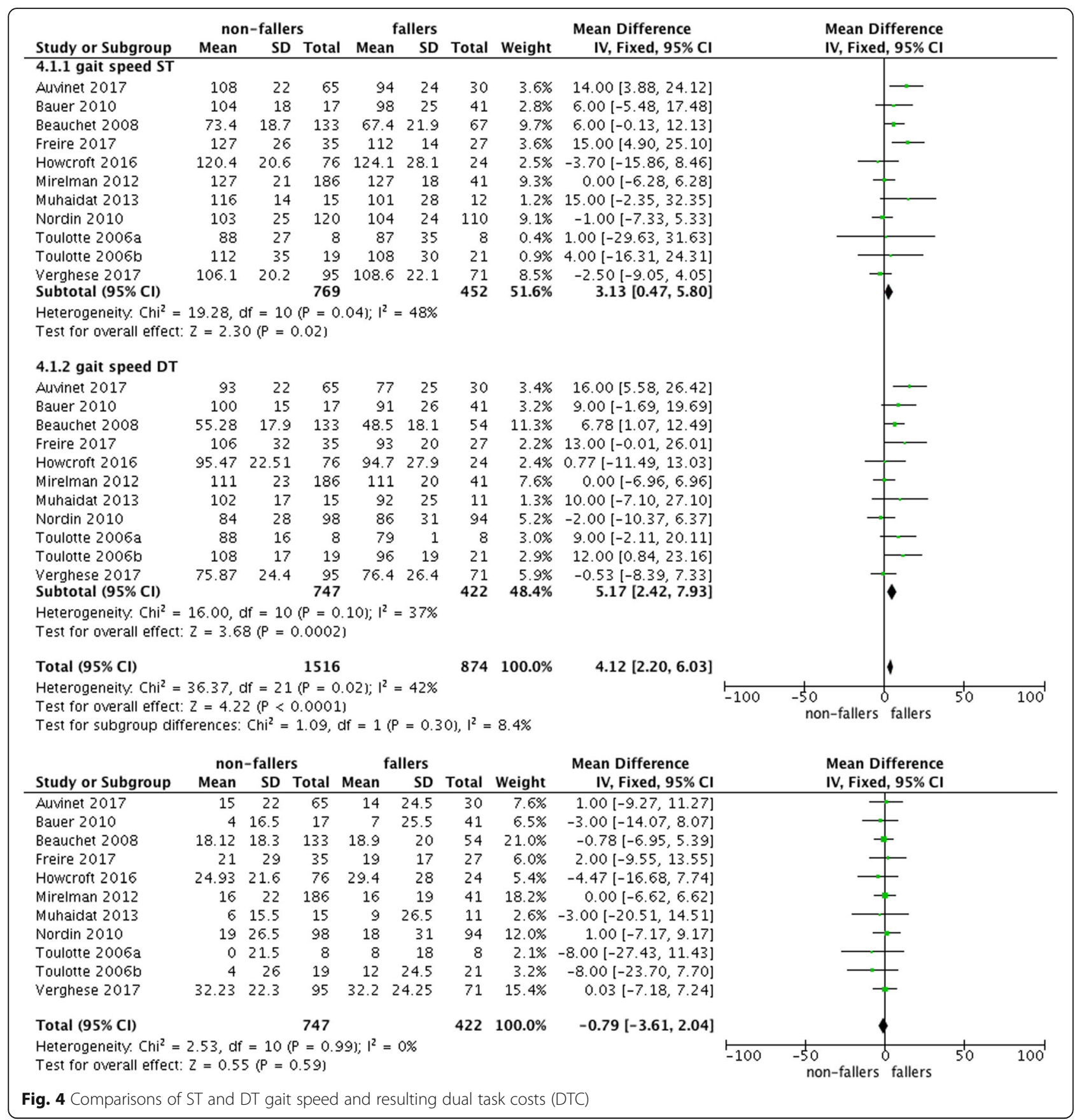

task. The study of Asai et al. [87] analysed an arithmetic DT situation and a motor-motor DT situation; and found that both tasks resulted in reduced walking speed. The motor-motor DT resulted in reduced (and therefore improved) body sway in ML and AP direction in comparison to the arithmetic DT situation. Reelick et al. [90] investigated an arithmetic DT situation and a verbal fluency task, and found no task differences. The meta-analysis revealed a significant difference of gait speed between participants with and without CoF under ST (mean difference: 12.41 [9.97-14.84]) and DT (mean difference: 10.61 [7.58-13.40]) conditions. The differences for the DTC failed to show significance (mean difference: 1.63 [- 1.01-4.27]; cf. Fig. 6).

\section{Discussion}

The aim of this systematic review and meta-analysis was to provide a taxonomy of different dual-task settings and test their relations to cognitive-motor decrements with fall risk and CoF. Additionally, the cognitive tasks were regarded separately with the purpose to find a dual-task 


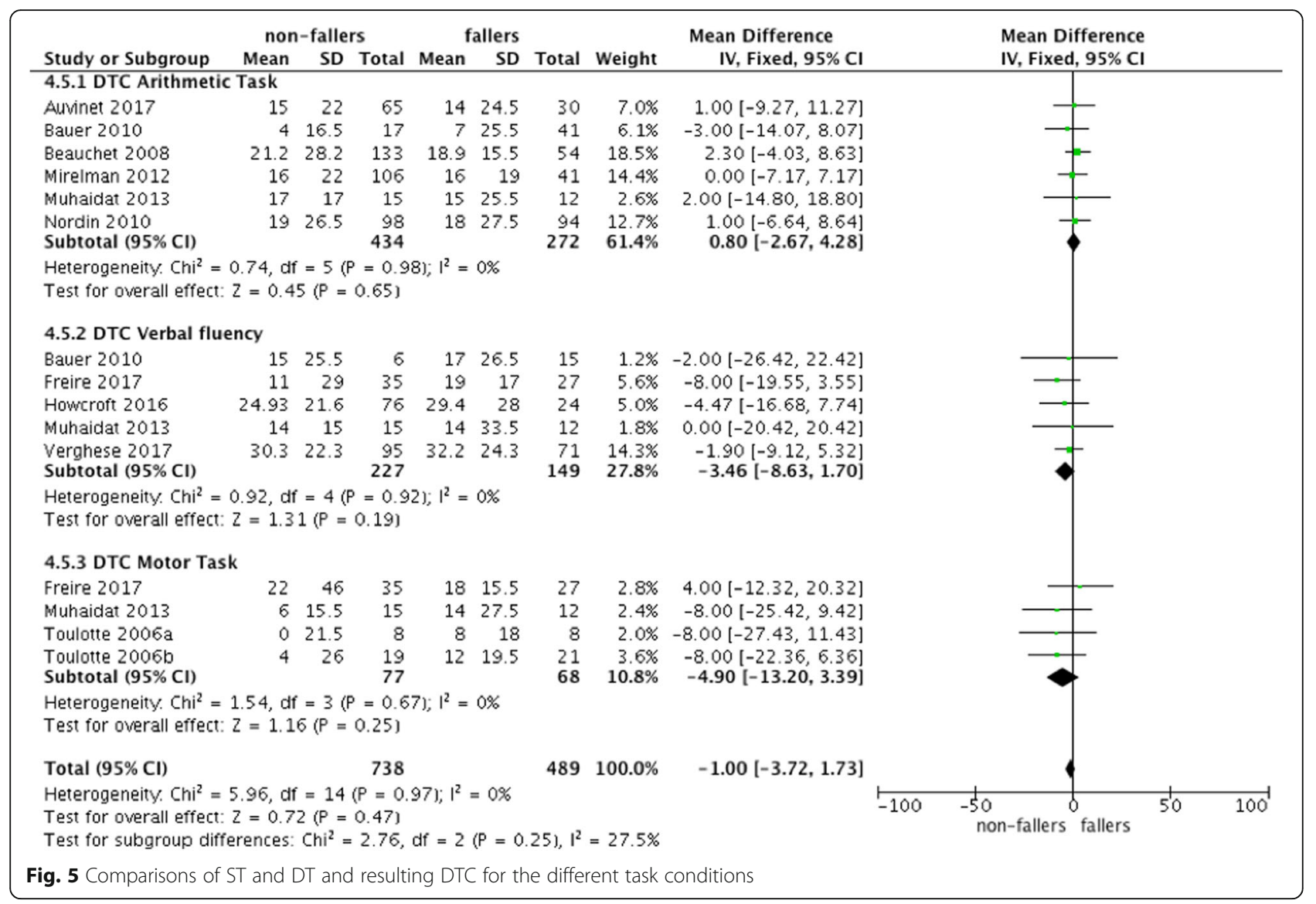

taxonomy or classification of the DT settings that are most beneficial to identify cognitive-motor interference in older fallers and older people with $\mathrm{CoF}$.

\section{Differences of DT performance on spatiotemporal gait parameters between non-fallers and fallers}

The results of the meta-analysis suggested that gait speed and cadence in ST and DT conditions can discriminate between fallers and non-fallers. Studies classifying people as fallers and non-fallers were based primarily on retrospective falls, with only two studies being prospective $[19,96]$. These results confirm previous systematic review evidence which showed differences in gait speed between fallers and non-fallers [50,68]. With regard to the associated DTC, only five of eleven studies found higher decrements in gait speed from ST to DT for fallers in comparison to non-fallers (Fig. 4). The overall DTC failed to be significant between these two groups in our meta-analysis. There were only small amounts of DTC for both groups and the standard deviations were large. In line with the results of other studies that could not be included in the meta-analysis, fallers and nonfallers both show decrements in gait speed in ST and DT conditions (cf. Table 5 and Fig. 4). These decrements are not significantly different between groups which is inconsistent with the hypothesis that non-fallers and fallers differ in their ability of task prioritization [16, 67]. Fallers walk significantly slower than non-fallers in ST conditions; however, step length and stride length, which are known to be highly correlated with gait speed [91], did not differ significantly between groups. Specific recommendations on whether or not cognitive-motor-interference increases fall risk cannot be provided. These results confirm the findings by Zijlstra et al. [68] and Menant et al. [50] who also reported no additional benefit of DT walking as a measurement to discriminate fallers from non-fallers. Nevertheless, it is important to note that gait performance includes different components of functional performance such as maximal walking velocity, gait economy, walking effectiveness, efficiency and safety. These aspects might be more relevant to estimate fall risk. Therefore, future studies should address these components of gait performance in tailored DT settings.

Differences of DT performance between participants with and without $\mathrm{CoF}$

People with CoF showed greater gait decrements under ST and DT conditions compared to people without 


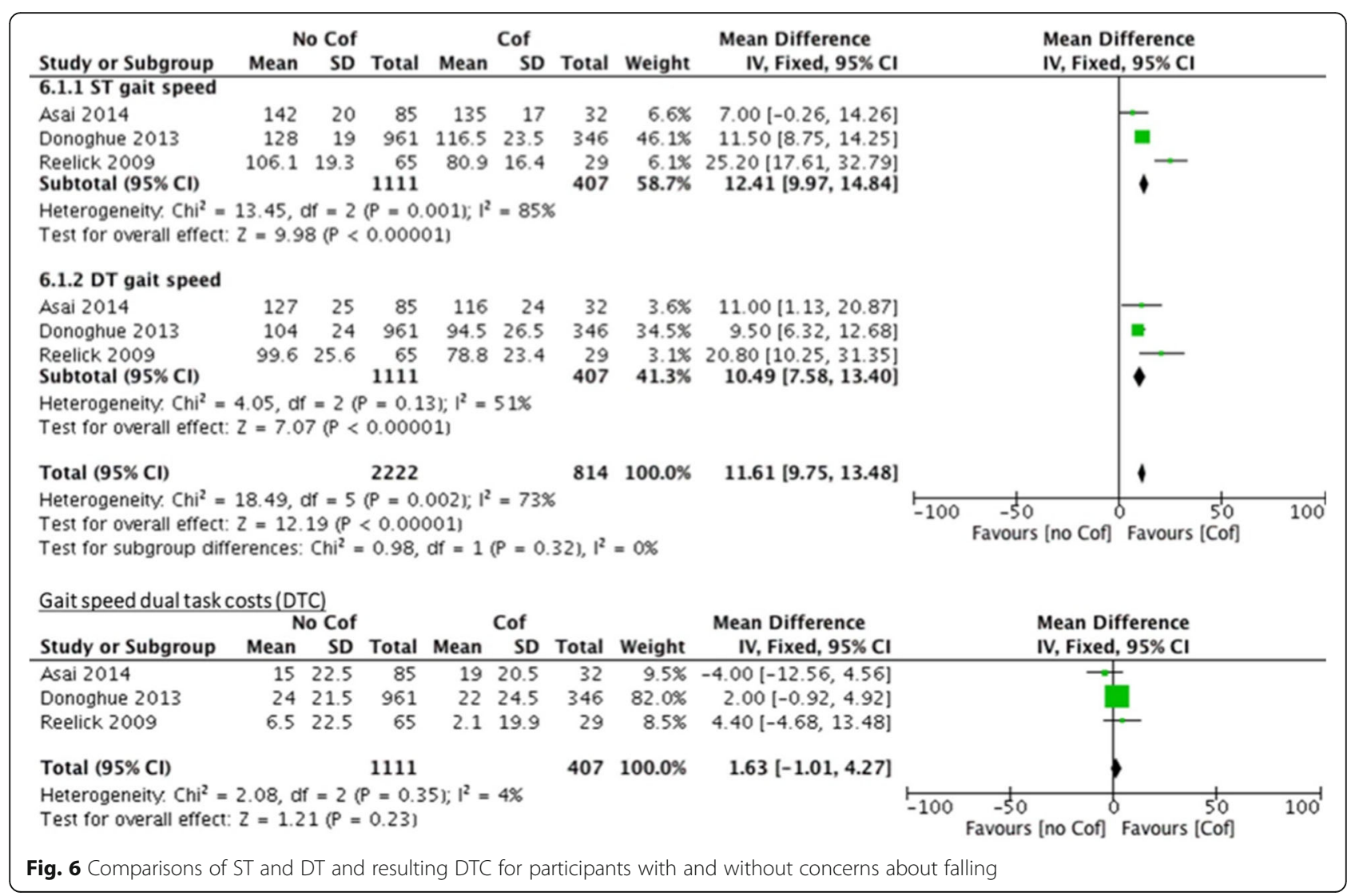

CoF. The overall effects from the meta-analysis suggested that the effects of CoF were larger (11.61; CI: 9.75-13.48) in fallers compared to non-fallers (4.12; CI: 2.20-6.03). CoF is common in people with and without a previous fall history and the prevalence rates are higher than falls themselves [93]. It has been suggested that people with CoF have difficulty inhibiting or ignoring irrelevant information of the environment when controlling their balance in complex and DT situations [40]. Many daily life activities include some level of dual-tasking in which executive functioning or performance (i.e. inhibition) are required. CoF might compete for these limited resources of attentional focus to maintain their balance [52], which would result in a more pronounced slowing of their walking speed under DT conditions (cf. Fig. 6) in people with $\mathrm{CoF}$ irrespective of their fall history or fall risk. However, our analyses were not able to confirm this hypothesis as DTC was not significantly different between people with and without CoF.

\section{Influence of the task condition}

A large variety of cognitive tasks have been used to assess cognitive-motor interference in the literature. As part of this review, a total of 11 different DTconditions were used to compare non-fallers and fallers on DT walking performance (Fig. 5). According to the proposed taxonomy (Table 1) mental tracking tasks, especially counting backward tasks by numbers in $1 \mathrm{~s}, 3 \mathrm{~s}$ or $7 \mathrm{~s}$ are the most commonly used task sets. Overall, we were able to compare three types of cognitive dual-tasks (i.e. arithmetic, verbal fluency and motor tasks) within the meta-analysis of this review. Two of them belong to the same category of our taxonomy (mental tracking, cf. Table 1). The third one included an additional motor task. However, all task settings affected DTC similarly, and the pooled effect (mean difference: - $1.00[-3.72-1.73]$ ) had low heterogeneity $\left(\mathrm{I}^{2}=0 \%\right)$.

Other cognitive tasks such as reaction time and decision making tasks for processing speed and controlled processing tasks, [92] were not integrated in the task setting of the included studies but could be relevant for navigating in daily traffic situations. In addition, previous studies have suggested that more complex tasks such as working memory tasks, discrimination tasks or visuospatial tasks would have a greater impact on the DTC (for an overview see Lacour et al. [52]) but this could not be confirmed by this review due to the limited studies using these tasks. Furthermore, within the 
available data there were also no marked differences between the different types of cognitive tasks. On the other hand, there is evidence that mental tracking tasks like verbal fluency tasks increase the DTC more significantly for fallers compared to nonfallers [81], due to the additional load on the working memory for these tasks. However, this review was not able to confirm this hypothesis. Finally, motor-motor DT condition also did not show significant differences in DTC between non-fallers and fallers. Both studies by Toulotte et al. [83, 84] suggested a more pronounced DTC when carrying in glass of water, suggesting this would slow participants down as they need to observe the glass of water in their hand. However, other studies have suggested the opposite [80], as a result of a forward flexion of the trunk when carrying a tray with a glass of water in front of the body.

\section{Implications of the results}

Similar to previous reviews, we were not able to confirm differences between fallers and non-fallers in DTC. One reason for this result might be that we were only able to compare three types of dual-task settings (i.e. arithmetic, verbal fluency and motor tasks) within the meta-analysis. Therefore, additional studies are required to examine the discriminatory ability of walking performance with and without concurrent reaction time, controlled processing, visuospatial, working memory and discrimination tasks. Study designs comparing different DT-settings in smaller samples [20] or randomised trials with a representative larger sample size could be used to systematically address different cognitive processes and their complexities. In addition, it might be important to consider an individual's biography before deciding on a DT. One might argue, that a maths teacher might find a counting backwards task more intuitive, while a librarian might be more comfortable with verbal fluency tasks. More work is required to test this hypothesis. Tasks that include visuo-spatial information processing or higher executive functions (e.g., inhibition within a Stroop-task) [2] might have greater potential in discriminating between fallers and nonfallers. These tasks may be less dependent on people's biography. However, these task-settings might be difficult to use in clinical settings and with short walking distances. In addition to the cognitive dimensions of the task settings, the walking conditions and parcourse need to be reflected, as a straight walking course does not sufficiently address real-life gait. The ongoing development of wearable technology might be one solution to overcome measurement set up problems.

\section{Limitations}

Overall, the quality of the included studies was good. Nevertheless, there are some issues that need to be discussed. First, spatiotemporal gait parameters were assessed using diverse measurement methods, varying between the crude use of a stopwatch to accelerometers and electronic walkways [94]. Second, there is not a common length of the walking tracks with many studies using distances that are too short to see a DT effect. According to Lindemann et al. [95], the distance to achieve a steady walking state increases with higher gait speed. Third, studies report different spatiotemporal gait parameters. Especially, spatiotemporal gait parameters related to balance, such as step width, double support time, gait stability and variability, were not reported frequently enough to be included in the meta-analysis. It is possible that the effect of DTC would be visible on such measures before it affects gait speed especially over short distances. Fourth, the short distances might influence prioritisation of the motor and cognitive tasks. The short distances also limit the time available for the cognitive dual-task, which might explain why the meta-analysis could not show a different cognitive-motor interference on gait between fallers and non-fallers. Finally, most of the studies did not report the motor and the cognitive DTC. This means that there is no control for the attentional focus of the participants, rendering it unclear if the performance decrements result from the attentional focus or from cognitivemotor interferences. Finally, to gain information about the influence of the DT taxonomy on DTC, this review integrated only studies with straight walking. This was necessary to overcome the problem that gait execution while changing directions, walking in curves or reacting to external perturbation, has a different impact on spatiotemporal gait parameters as well on the cognitive performance.

\section{Conclusions}

Overall, the large diversity of studies and types of cognitive dual-tasks do not allow us to provide conclusive recommendations for clinical testing of cognitive-motor interference while walking. In agreement with previous studies $[50,78]$, we found no additional benefit of DT gait analysis to differentiate between fallers and non-fallers. Similar results were found when comparing people with and without CoF. However, our analyses also reveal that several domains of cognitive dual-tasks have not yet been investigated. The proposed cognitive task taxonomy will assist in systematic assessment of these tasks and their effect on gait. 


\section{Appendix}

Table $\mathbf{8}$ Search strategy

\begin{tabular}{|c|c|c|c|}
\hline \multirow[t]{2}{*}{ Keywords } & \multicolumn{3}{|c|}{ Papers identified } \\
\hline & Medline & EMBASE & Psyclnfo \\
\hline $\begin{array}{l}\text { 1. "Age" or "old\$" or "elder\$" or "aged" or "advanced age" or "senior\$" or "geriatric\$" or "eldest" or "aging" or } \\
\text { "gerontic" or "faller\$" or "fear of falling" }\end{array}$ & 10.451 .411 & 7.016 .103 & 1.097 .778 \\
\hline $\begin{array}{l}\text { 2. "corresponding task\$" or "coupled task\$" or "dual task\$" or "dual task paradigm\$" or "secondary task" or } \\
\text { "conflicting task" or "task prioritisation" or "inattentional blindness" }\end{array}$ & 4.200 & 167.739 & 56.654 \\
\hline 3. "gait" or "step length" or "cadence" or "step count" or "step width" or "stance time" or "swing time" or "s & 1.198 .325 & 1.374 .933 & 349.516 \\
\hline
\end{tabular}
support time" or "stride time" or "stride width" or "stride length" or "gait line" or "maximum force forefoot" or "maximum force midfoot" or "maximum force heel" or "double support time" or "gait speed" or "stride speed" or "motion" or "movement\$" or "motor\$" or "locomotion" or "walking" or "balance" or "posture" not "slipping" (not "perturbation")

4. "cognitive" or "neurocognitive" or "cognition\$" or "executive" or "processing" or "spatial" or "visuospatial" or "memory" or "reaction\$" or "speed" or "decision-making" or "mental" or "attention" or "cognitive-motor" or "motorcognitive" or "reaction\$" or "planning" or inhibition

5. Combination of 1 and 2 and 3 and 4

$1.515 \quad 658 \quad 1.134$

\section{Acknowledgements}

We thank Liesann Seydell for her assistance in formatting the manuscript including the tables.

\section{Authors' contributions}

The manuscript was written by BW with the help of MS, KVS and KD. The search was conducted by BW and MW independently. The quality assessment was done by BW and MS and reviewed by KVS. The metaanalysis was done by BW and KD. All authors read and approved the final manuscript.

\section{Funding}

There was no funding received for this study.

\section{Availability of data and materials}

The supporting data is available via the corresponding author.

\section{Ethics approval and consent to participate}

There was no Ethical approval required as the study was a systematic review.

This review was registered at Prospero with the ID: CRD42017068912.

\section{Consent for publication}

All authors have approved the manuscript and agree with its submission to "European Review of Aging and Physical activity".

\section{Competing interests}

The authors declare that they have no competing interests.

\section{Author details}

${ }^{1}$ Human Movement Science, University of Hamburg, Mollerstr, 10, 20148 Hamburg, Germany. ${ }^{2}$ Department for Occupational Medicine, Hazardous Substances and Public Health, German Social Accident Insurance for the Health and Welfare Services, Hamburg, Germany. ${ }^{3}$ Neuroscience Research Australia, University of New South Wales, Sydney, Australia.

Received: 15 March 2019 Accepted: 2 July 2019

Published online: 27 July 2019

\section{References}

1. Al-Yahya E, Dawes H, Smith L, Dennis A, Howells K, Cockburn J. Cognitive motor interference while walking: A systematic review and meta-analysis. Neurosci Biobehav Rev. 2011:35(3):715-28.

2. Bock O. Dual-task costs while walking increase in old age for some, but not for other tasks: an experimental study of healthy young and elderly persons. J Neuroeng Rehabil. 2008;5(1):27.
3. Hollman JH, Kovash FM, Kubik JJ, Linbo RA. Age-related differences in spatiotemporal markers of gait stability during dual task walking. Gait Posture. 2007;26(1):113-9.

4. Wollesen B, Mattes K, Rönnfeldt J. Influence of age, gender and test conditions on the reproducibility of dual-task walking performance.Aging clinical and experimental research. 2017:29(4):761-69.

5. Beurskens R, Bock O. Age-related deficits of dual-task walking: a review. Neural Plast. 2012;2012(4):1-9.

6. Lindenberger $U$, Marsiske $M$, Baltes PB. Memorizing while walking: increase in dual-task costs from young adulthood to old age. Psychol Aging. 2000; 15(3):417-36.

7. Collin G, van den Heuvel MP. The ontogeny of the human connectome development and dynamic changes of brain connectivity across the life span. Neuroscientist. 2013;19(6):616-28.

8. Hedman AM, van Haren NEM, Schnack HG, Kahn RS, Hulshoff Pol HE. Human brain changes across the life span: a review of 56 longitudinal magnetic resonance imaging studies. Hum Brain Mapp. 2012;33(8):1987-2002.

9. Hedden T, Gabrieli JDE. Insights into the ageing mind: a view from cognitive neuroscience. Nat Rev Neurosci. 2004;5(2):87-96.

10. Faulkner KA, Redfern MS, Cauley JA, Landsittel DP, Studenski SA, Rosano C, et al. Multitasking: association between poorer performance and a history of recurrent falls. J Am Geriatr Soc. 2007;55(4):570-6.

11. Li KZH, Lindenberger $U$. Relations between aging sensory/sensorimotor and cognitive functions. Neurosci Biobehav Rev. 2002;26(7):777-83.

12. Holtzer $\mathrm{R}$, Wang $C$, Verghese J. Performance variance on walking while talking tasks: theory, findings, and clinical implications. Age. 2014;36(1):373-81.

13. Cornu V, Steinmetz J-P, Federspiel C. Deficits in selective attention alter gait in frail older adults. GeroPsych. 2016;29(1):29-36.

14. MacAulay RK, Allaire TD, Brouillette RM, Foil HC, Bruce-Keller AJ, Han H, et al Longitudinal assessment of neuropsychological and temporal/spatial gait characteristics of elderly fallers: taking it all in stride. Front Aging Neurosci. 2015;7:70.

15. Amboni M, Barone P, Hausdorff JM. Cognitive contributions to gait and falls: evidence and implications. Mov Disord. 2013:28(11):1520-33.

16. Muir-Hunter SW, Wittwer JE. Dual-task testing to predict falls in community-dwelling older adults: a systematic review. Physiotherapy. 2016;102(1):29-40

17. van Schooten KS, Freiberger E, Smitt MS, Keppner V, Sieber C, Lord SR, Delbaere K. Concern About Falling Is Associated With Gait Speed, Independently From Physical and Cognitive Function. Physical Therapy. 2019;pzz032:1-21. https://doi.org/10.1093/ptj/pzz032.

18. Maki BE. Gait changes in older adults: predictors of falls or indicators of fear. I Am Geriatr Soc. 1997:45(3):313-20.

19. Beauchet O, Annweiler C, Allali G, Berrut G, Herrmann FR, Dubost V. Recurrent falls and dual task-related decrease in walking speed: is there a relationship? J Am Geriatr Soc. 2008;56(7):1265-9. 
20. Muhaidat J, Kerr A, Evans JJ, Skelton DA. The test-retest reliability of gaitrelated dual task performance in community-dwelling fallers and non-fallers. Gait Posture. 2013;38(1):43-50.

21. Freire Júnior RC, Porto JM, Marques NR, Magnani PE, Abreu DC. The effects of a simultaneous cognitive or motor task on the kinematics of walking in older fallers and non-fallers. Hum Mov Sci. 2017;51:146-52.

22. Nagamatsu LS, Voss M, Neider MB, Gaspar JG, Handy TC, Kramer AF, LiuAmbrose TYL. Increased cognitive load leads to impaired mobility decisions in seniors at risk for falls. Psychol Aging. 2011;26(2):253-9.

23. Neider MB, Gaspar JG, McCarley JS, Crowell JA, Kaczmarski H, Kramer AF. Walking and talking: dual-task effects on street crossing behavior in older adults. Psychol Aging. 2011;26(2):260-8.

24. Craik Fl, Salthouse TA, editors. The handbook of aging and cognition. New York: Psychology Press; 2011. p. 3.

25. Colcombe S, Kramer AF. Fitness effects on the cognitive function of older adults: a meta-analytic study. Psychol Sci. 2003;14(2):125-30.

26. Strauss E, Sherman EM, Spreen O. A compendium of neuropsychological tests: Administration, norms, and commentary. New York: Oxford University Press; 2006. p.3

27. Lezak MD, Howieson DB, Loring DW, Fischer JS. Neuropsychological assessment. USA: Oxford University Press; 2004

28. Manna CG, Alterescu K, Borod JC, Bender HA. Benton visual retention test. In: Encyclopedia of clinical neuropsychology. New York: Springer; 2011. p. 392-4

29. Williams JMG, Mathews A, MacLeod C. The emotional Stroop task and psychopathology. Psychol Bull. 1996;120(1):3.

30. Baddeley A, Logie R, Bressi S, Sala SD, Spinnler H. Dementia and working memory. Q J Exp Psychol A Hum Exp Psychol. 1986;38(4):603-18.

31. D'Esposito M, Postle BR, Ballard D, Lease J. Maintenance versus manipulation of information held in working memory: an event-related fMRI study. Brain Cogn. 1999;41(1):66-86.

32. Barde LH, Thompson-Schill SL. Models of functional organization of the lateral prefrontal cortex in verbal working memory: evidence in favor of the process model. J Cogn Neurosci. 2002;14(7):1054-63.

33. MacLeod CM. Half a century of research on the Stroop effect: an integrative review. Psychol Bull. 1991;109(2):163.

34. Pashler H. Dual-task interference in simple tasks: data and theory. Psychol Bull. 1994;116(2):220-44.

35. Pashler H, Johnston JC, Ruthruff E. Attention and performance. Annu Rev Psychol. 2001;52(1):629-51.

36. Welford AT. Single-channel operation in the brain. Acta Psychol. 1967;27:5-22

37. Wickens CD. Multiple resources and performance prediction. Theor Issues Ergon Sci. 2002;3(2):159-77

38. Sherrington C, Tiedemann A, Fairhall N, Close JCT, Lord SR. Exercise to prevent falls in older adults: an updated meta-analysis and best practice recommendations. N S W Public Health Bull. 2011;22(4):78.

39. Eysenck MW, Derakshan N, Santos R, Calvo MG. Anxiety and cognitive performance: attentional control theory. Emotion. 2007;7(2):336.

40. Young WR, Mark Williams A. How fear of falling can increase fall-risk in olde adults: applying psychological theory to practical observations. Gait Posture. 2015:41(1):7-12

41. Ayoubi F, Launay CP, Annweiler C, Beauchet O. Fear of falling and gait variability in older adults: a systematic review and meta-analysis. J Am Med Dir Assoc. 2015;16(1):14-9.

42. Donoghue OA, Dooley C, Kenny RA. Usual and dual-task walking speed: implications for pedestrians crossing the road. J Aging Health. 2016b; 28(5):850-62.

43. Navon D, Gopher D. On the economy of the human-processing system. Psychol Rev. 1979;86(3):214-55.

44. Spirduso WW, Francis KL, MacRae PG. Physical dimensions of aging. 2nd ed. Champaign: Human Kinetics; 2005.

45. Guttman SE, Gilroy LA, Blake R. Hearing what the eyes see: auditory encoding of visual temporal sequences. Psychol Sci. 2005;16(3):228-35

46. Patel P, Lamar M, Bhatt T. Effect of type of cognitive task and walking speed on cognitive-motor interference during dual-task walking. Neuroscience. 2014:260:140-8

47. Hall CD, Echt KV, Wolf SL, Rogers WA. Cognitive and motor mechanisms underlying older adults' ability to divide attention while walking. Phys Ther. 2011;91(7):1039-50.

48. Li C, Verghese J, Holtzer R. A comparison of two walking while talking paradigms in aging. Gait Posture. 2014;40(3):415-9.
49. Maclean LM, Brown LJE, Khadra H, Astell AJ. Observing prioritization effects on cognition and gait: the effect of increased cognitive load on cognitively healthy older adults' dual-task performance. Gait Posture. 2017;53:139-44.

50. Menant JC, Schoene D, Sarofim M, Lord SR. Single and dual task tests of gait speed are equivalent in the prediction of falls in older people: a systematic review and meta-analysis. Ageing Res Rev. 2014;16:83-104.

51. Venema DM, Bartels E, Siu KC. Tasks matter: a cross-sectional study of the relationship of cognition and dual-task performance in older adults. J Geriatr Phys Ther. 2013;36(3):115-22.

52. Lacour M, Bernard-Demanze L, Dumitrescu M. Posture control, aging, and attention resources: models and posture-analysis methods. Clin Neurophysiol. 2008;38(6):411-21.

53. Riby L, Perfect T, Stollery B. The effects of age and task domain on dual task performance: A meta-analysis. Eur J Cogn Psychol. 2004;16(6):863-91.

54. Swan L, Otani H, Loubert PV, Sheffert SM, Dunbar GL. Improving balance by performing a secondary cognitive task. Br J Psychol. 2004;95(1):31-40.

55. Huxhold O, Li S-C, Schmiedek F, Lindenberger U. Dual-tasking postural control: aging and the effects of cognitive demand in conjunction with focus of attention. Brain Res Bull. 2006:69(3):294-305.

56. Riley MA, Baker AA, Schmit JM. Inverse relation between postural variability and difficulty of a concurrent short-term memory task. Brain Res Bull. 2003; 62(3):191-5

57. Wulf G, Mercer J, McNevin N, Guadagnoli MA. Reciprocal influences of attentional focus on postural and suprapostural task performance. J Mot Behav. 2004;36(2):189-99.

58. Vuillerme N, Nafati G. How attentional focus on body sway affects postural control during quiet standing. Psychol Res. 2007;71(2):192-200.

59. Stoffregen TA, Pagulayan RJ, Bardy BG, Hettinger LJ. Modulating postural control to facilitate visual performance. Hum Mov Sci. 2000;19(2):203-20.

60. Stoffregen TA, Smart LJ, Bardy BG, Pagulayan RJ. Postural stabilization of looking. J Exp Psychol Hum Percept Perform. 1999;25(6):1641-58.

61. Stoffregen TA, Hove P, Bardy BG, Riley M, Bonnet CT. Postural stabilization of perceptual but not cognitive performance. J Mot Behav. 2007;39(2):126-38.

62. Yogev-Seligmann G, Rotem-Galili Y, Mirelman A, Dickstein R, Giladi N, Hausdorff JM. How does explicit prioritization alter walking during dual-task performance? Effects of age and sex on gait speed and variability. Phys Ther. 2010;90(2):177-86.

63. Brown LA, Sleik RJ, Polych MA, Gage WH. Is the prioritization of postural control altered in conditions of postural threat in younger and older adults? J Gerontol A Biol Sci Med Sci. 2002:57(12):M785-92.

64. Chapman GJ, Hollands MA. Evidence that older adult fallers prioritise the planning of future stepping actions over the accurate execution of ongoing steps during complex locomotor tasks. Gait Posture. 2007;26(1):59-67.

65. Li KZ, Lindenberger U, Freund AM, Baltes PB. Walking while memorizing: age-related differences in compensatory behavior. Psychol Sci. 2001;12(3):230-7.

66. Yogev-Seligmann G, Hausdorff JM, Giladi N. Do we always prioritize balance when walking? Towards an integrated model of task prioritization. Mov Disord. 2012;27(6):765-70.

67. Schaefer S, Schumacher $V$. The interplay between cognitive and motor functioning in healthy older adults: findings from dual-task studies and suggestions for intervention. Gerontology. 2011;57(3):239-46.

68. Zijlstra A, Ufkes T, Skelton DA, Lundin-Olsson L, Zijlstra W. Do dual tasks have an added value over single tasks for balance assessment in fall prevention programs? A mini-review. Gerontology. 2008;54(1):40-9.

69. Yardley L, Beyer N, Hauer K, Kempen G, Piot-Ziegler C, Todd C. Development and initial validation of the falls efficacy scale-international (FES-I). Age Ageing. 2005;34(6):614-9.

70. Powell LE, Myers AM. The activities-specific balance confidence (ABC) scale. J Gerontol Ser A Biol Med Sci. 1995;50(1):M28-34.

71. Kmet LM, Cook LS, Lee RC. Standard quality assessment criteria for evaluating primary research papers from a variety of fields. Alberta: Alberta Heritage Foundation for Medical Research; 2014. https://www.ihe.ca/ download/standard_quality_assessment_criteria_for_evaluating_primary_ research_papers_from_a_variety_of_fields.pdf,08.07.19.

72. American Psychological Association. Publication manual. Washington, DC: American Psychological Association; 2016

73. Beauchet O, Allali G, Sekhon H, Verghese J, Guilain S, Steinmetz JP, et al. Guidelines for assessment of gait and reference values for spatiotemporal gait parameters in older adults: the biomathics and Canadian gait consortiums initiative. Front Hum Neurosci. 2017;11:353. 
74. Auvinet B, Touzard C, Montestruc F, Delafond A, Goeb V. Gait disorders in the elderly and dual task gait analysis: a new approach for identifying motor phenotypes. J Neuroeng Rehabil. 2017;14(1):7.

75. Bauer C, Gröger I, Glabasnia A, Bergler C, Gassmann KG. First results of evaluation of a falls clinic. Int J Gerontol. 2010;4(3):130-6.

76. Bootsma-van der Wiel A, Gussekloo J, De Craen AJ, Van Exel E, Bloem BR, Westendorp RG. Walking and talking as predictors of falls in the general population: the Leiden 85-plus study. J Am Geriatr Soc. 2003;51(10):1466-71.

77. Howcroft J, Kofman J, Lemaire ED, Mcllroy WE. Analysis of dual-task elderly gait in fallers and non-fallers using wearable sensors. J Biomech. 2016;49(7):992-1001.

78. Johansson J, Nordström A, Nordström P. Greater fall risk in elderly women than in men is associated with increased gait variability during multitasking. J Am Med Dir Assoc. 2016;17(6):535-40.

79. Mirelman A, Herman T, Brozgol M, Dorfman M, Sprecher E, Schweiger A, et al. Executive function and falls in older adults: new findings from a five-year prospective study link fall risk to cognition. PLoS One. 2012;7(6):e40297.

80. Nordin E, Moe-Nilssen R, Ramnemark A, Lundin-Olsson L. Changes in stepwidth during dual-task walking predicts falls. Gait Posture. 2010;32(1):92-7.

81. Reelick MF, Kessels RP, Faes MC, Weerdesteyn V, Esselink RA, Rikkert MGO. Increased intra-individual variability in stride length and reaction time in recurrent older fallers. Aging Clin Exp Res. 2011;23(5-6):393-9.

82. Springer S, Giladi N, Peretz C, Yogev G, Simon ES, Hausdorff JM. Dualtasking effects on gait variability: the role of aging, falls, and executive function. Mov Disord. 2006;21(7):950-7.

83. Toulotte $\mathrm{C}$, Thevenon A, Fabre $\mathrm{C}$. Effects of training and detraining on the static and dynamic balance in elderly fallers and non-fallers: a pilot study. Disabil Rehabil. 2006;28(2):125-33.

84. Toulotte C, Thevenon A, Watelain E, Fabre C. Identification of healthy elderly fallers and non-fallers by gait analysis under dual-task conditions. Clin Rehabil. 2006;20(3):269-76.

85. Verghese J, Wang C, Ayers E, Izzetoglu M, Holtzer R. Brain activation in highfunctioning older adults and falls: prospective cohort study. Neurology. 2017;88(2):191-97.

86. Yamada M, Aoyama T, Nakamura M, Tanaka B, Nagai K, Tatematsu N, et al. The reliability and preliminary validity of game-based fall risk assessment in community-dwelling older adults. Geriatr Nurs. 2011;32(3):188-94.

87. Asai T, Misu S, Doi T, Yamada M, Ando H. Effects of dual-tasking on contro of trunk movement during gait: respective effect of manual-and cognitivetask. Gait Posture. 2014;39(1):54-9.

88. Donoghue OA, Cronin H, Savva GM, O'Regan C, Kenny RA. Effects of fear of falling and activity restriction on normal and dual task walking in community dwelling older adults. Gait Posture. 2013;38(1):120-4.

89. Reelick MF, van lersel MB, Kessels RP, Rikkert MGO. The influence of fear of falling on gait and balance in older people. Age Ageing. 2009:38(4):435-40.

90. Wollesen B, Schulz S, Seydell L, Delbaere K. Does dual task training improve walking performance of older adults with concern of falling? BMC Geriatr. 2017;17(1):213

91. Perry J. Gait analysis: normal and pathodological function. 2nd ed. New York: SLACK Inc.; 2010.

92. Aksan N, Anderson SW, Dawson J, Uc E, Rizzo M. Cognitive functioning differentially predicts different dimensions of older drivers' on-road safety. Accid Anal Prev. 2015;75:236-44.

93. Rochat S, Büla CJ, Martin E, Seematter-Bagnoud L, Karmaniola A, Aminian K, et al. What is the relationship between fear of falling and gait in wellfunctioning older persons aged 65 to 70 years? Arch Phys Med Rehabil. 2010;91(6):879-84.

94. Youdas JW, Hollman JH, Aalbers MJ, Ahrenholz HN, Aten RA, Cremers JJ. Agreement between the GAITRite walkway system and a stopwatch-footfall count method for measurement of temporal and spatial gait parameters. Arch Phys Med Rehabil. 2006;87(12):1648-52.

95. Lindemann U, Najafi B, Zijlstra W, Hauer K, Muche R, Becker C, Aminian K. Distance to achieve steady state walking speed in frail elderly persons. Gait Posture. 2008;27(1):91-6.

96. Beauchet O, Allali G, Annweiler C, Berrut G, Maarouf N, Herrmann FR, Dubost $V$. Does change in gait while counting backward predict the occurrence of a first fall in older adults? Gerontology. 2008;54(4):217-23.

97. Kressig RW, Herrmann FR, Grandjean R, Michel JP, Beauchet O. Gait variability while dual-tasking: fall predictor in older inpatients? Aging Clin Exp Res. 2008;20(2):123-30
98. Hadjistavropoulos T, Carleton RN, Delbaere K, Barden J, Zwakhalen S, Fitzgerald $\mathrm{B}$, et al. The relationship of fear of falling and balance confidence with balance and dual tasking performance. Psychol Aging. 2012;27(1):1-13.

99. Halvarsson A, Olsson E, Farén E, Pettersson A, Ståhle A. Effects of new, individually adjusted, progressive balance group training for elderly people with fear of falling and tend to fall: a randomized controlled trial. Clin Rehabil. 2011;25(11):1021-31.

100. Halvarsson A, Franzén E, Farén E, Olsson E, Oddsson L, Ståhle A. Long-term effects of new progressive group balance training for elderly people with increased risk of falling - a randomized controlled trial. Clin Rehabil. 2013; 27(5):450-8

101. Herman T, Mirelman A, Giladi N, Schweiger A, Hausdorff JM. Executive control deficits as a prodrome to falls in healthy older adults: a prospective study linking thinking, walking, and falling. J Gerontol A Biol Sci Med Sci. 2010:65(10):1086-92

102. MacAulay RK, Allaire TD, Brouillette RM, Foil HC, Bruce-Keller AJ, Han H, et al. Longitudinal assessment of neuropsychological and temporal/spatial gait characteristics of elderly fallers: taking it all in stride. Front Aging Neurosci. 2015;7:34.

103. Rinaldi NM, Moraes R. Older adults with history of falls are unable to perform walking and prehension movements simultaneously. Neuroscience. 2016:316:249-60.

104. Rogan S, Taeymans J, Bangerter C, Simon S, Terrier P, Hilfiker R. Einfluss von Einfach- und Doppelaufgaben auf Gangstabilitat und Ganggeschwindigkeit bei alteren Menschen: Eine explorative Studie, [Influence of single and dual tasks on gait stability and gait speed in the elderly : an explorative study]. Z Gerontol Geriatr. 2019;52(1):23-7

105. Yogev G, Plotnik M, Peretz C, Giladi N, Hausdorff JM. Gait asymmetry in patients with Parkinson's disease and elderly fallers: when does the bilateral coordination of gait require attention? Exp Brain Res. 2007;177(3):336-46.

\section{Publisher's Note}

Springer Nature remains neutral with regard to jurisdictional claims in published maps and institutional affiliations.

Ready to submit your research? Choose BMC and benefit from:

- fast, convenient online submission

- thorough peer review by experienced researchers in your field

- rapid publication on acceptance

- support for research data, including large and complex data types

- gold Open Access which fosters wider collaboration and increased citations

- maximum visibility for your research: over $100 \mathrm{M}$ website views per year

At $\mathrm{BMC}$, research is always in progress.

Learn more biomedcentral.com/submissions 